\title{
Application of SCIAMACHY and MOPITT CO total column measurements to evaluate model results over biomass burning regions and Eastern China
}

\author{
C. Liu ${ }^{1}$, S. Beirle ${ }^{1}$, T. Butler ${ }^{1}$, J. Liu ${ }^{2}$, P. Hoor ${ }^{1, *}$, P. Jöckel ${ }^{1, * *}$, M. Penning de Vries ${ }^{1}$, A. Pozzer ${ }^{1,3}$, C. Frankenberg ${ }^{4}$, \\ M. G. Lawrence ${ }^{1}$, J. Lelieveld ${ }^{1,3}$, U. Platt ${ }^{5}$, and T. Wagner ${ }^{1}$ \\ ${ }^{1}$ Max-Planck-Institute for Chemistry, Mainz, Germany \\ ${ }^{2}$ Air Quality Research Division Environment Canada, Downsview, Ontario, Canada \\ ${ }^{3}$ Cyprus Institute, Nicosia, Cyprus \\ ${ }^{4}$ Jet Propulsion Laboratory, California Institute of Technology, Pasadena, USA \\ ${ }^{5}$ Institute for Environmental Physics, University of Heidelberg, Heidelberg, Germany \\ * now at: Institute for Atmospheric Physics, University Mainz, Mainz, Germany \\ ** now at: Institut für Physik der Atmosphäre, Deutsches Zentrum für Luft- und Raumfahrt (DLR), \\ Oberpfaffenhofen, Germany
}

Received: 15 November 2010 - Published in Atmos. Chem. Phys. Discuss.: 17 January 2011

Revised: 6 June 2011 - Accepted: 17 June 2011 - Published: 29 June 2011

\begin{abstract}
We developed a new $\mathrm{CO}$ vertical column density product from near IR observations of the SCIAMACHY instrument onboard ENVISAT. For the correction of a temporally and spatially variable offset of the $\mathrm{CO}$ vertical column densities we apply a normalisation procedure based on coincident MOPITT (version 4) observations over the oceans. The resulting normalised SCIAMACHY CO data is well suited for the investigation of the CO distribution over continents, where important emission sources are located. We use only SCIAMACHY observations for effective cloud fractions below $20 \%$. Since the remaining effects of clouds can still be large (up to $100 \%$ ), we applied a cloud correction scheme which explicitly considers the cloud fraction, cloud top height and surface albedo of individual observations. The normalisation procedure using MOPITT data and the cloud correction substantially improve the agreement with independent data sets. We compared our new SCIAMACHY $\mathrm{CO}$ data set, and also observations from the MOPITT instrument, to the results from three global atmospheric chemistry models (MATCH, EMAC at low and high resolution, and GEOS-Chem); the focus of this comparison is on regions with strong $\mathrm{CO}$ emissions (from biomass burning or anthropogenic sources). The comparison indicates that over most of these regions the seasonal cycle is generally captured well but the simulated $\mathrm{CO}$ vertical column densities
\end{abstract}

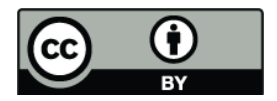

Correspondence to: T. Wagner (thomas.wagner@mpic.de) are systematically smaller than those from the satellite observations, in particular with respect to SCIAMACHY observations. Because SCIAMACHY is more sensitive to the lowest part of the atmosphere compared to MOPITT, this indicates that especially close to the surface the model simulations systematically underestimate the true atmospheric $\mathrm{CO}$ concentrations, probably caused by an underestimation of $\mathrm{CO}$ emissions by current emission inventories. For some biomass burning regions, however, such as Central Africa in July-August, model results are also found to be higher than the satellite observations.

\section{Introduction}

Atmospheric carbon monoxide $\mathrm{CO}$ is released by natural and anthropogenic sources such as biomass burning or fossil fuel combustion. $\mathrm{CO}$ is toxic in high concentrations and an important precursor of tropospheric ozone (e.g. Crutzen and Gidel, 1983). It is the major sink for the $\mathrm{OH}$ radical and thus strongly influences the oxidative capacity of the atmosphere. With a lifetime of typically weeks to months (Cicerone, 1988) it is a good tracer for long range atmospheric transport (Logan et al., 1981; Lelieveld et al., 2001; Shindell et al., 2006). The main sources of atmospheric carbon monoxide are relatively well understood (Galanter et al., 2000; Granier et al., 2000; Holloway et al., 2000), but the magnitude of individual sources and their seasonality,

Published by Copernicus Publications on behalf of the European Geosciences Union. 
especially of biomass burning, are still not well known. In this study we use satellite observations of the SCanning Imaging Absorption SpectroMeter for Atmospheric ChartographY (SCIAMACHY) on the Environmental Satellite (ENVISAT) (Burrows et al., 1995; Bovensmann et al., 1999) to assess the skills of three atmospheric models to simulate the atmospheric $\mathrm{CO}$ concentrations. Emphasis is on regions with intense biomass burning or anthropogenic pollution.

SCIAMACHY observes scattered and reflected sunlight. Thus, its sensitivity to trace gases close to the surface is larger than for observations in the thermal IR (like from the Measurements of Pollution in the Troposphere (MOPITT) instrument, see e.g., Drummond and Mand, 1996; Deeter et al., 2003). Hence, SCIAMACHY observations are especially well suited to constrain the CO concentrations close to the sources. Different research groups have developed retrieval algorithms for CO from SCIAMACHY, which are based on modified Differential Optical Absorption Spectroscopy (DOAS) retrievals (Platt and Stutz, 2008) because of the peculiarities in the near IR-spectral range. The so called Iterative Maximum Likelihood Method (IMLM) was developed at the Netherlands Institute for Space Research (SRON) (Gloudemans et al., 2004; Gloudemans et al., 2005; de Laat et al., 2006), the Weighting Function Modified (WFM)-DOAS algorithm was developed at the University of Bremen (Buchwitz et al., 2000, 2004, 2006a), and the Iterative Maximum A Posteriori (IMAP)-DOAS method was developed at the University of Heidelberg (Frankenberg et al., 2005a,b). In our study we use the IMAP-DOAS algorithm, but we apply two important additional corrections, which are described in detail below. The resulting data set of the $\mathrm{CO}$ vertical column density (the vertically integrated $\mathrm{CO}$ concentration, $\mathrm{VCD}$ ) is well suited for the quantitative investigation of the distribution of the CO VCD over the continents, especially in combination with other satellite observations and/or results from model simulations.

Many comparisons of CO VCDs from SCIAMACHY with other satellite observations (mainly MOPITT) and model results have been performed in recent years (e.g., Buchwitz et al., 2004, 2006a, 2007; Gloudemans et al., 2005; Straume et al., 2005; Turquety et al., 2008; Tangborn et al., 2009; de Laat et al., 2010; Kopacz et al., 2010). Besides for validation purposes, the aim of these comparisons was also the improvement of emission estimates. Models were also used as "transfer tools" for the comparison of CO VCDs from SCIAMACHY with those from other satellite sensors (e.g., Turquety et al., 2008; Kopacz et al., 2010; de Laat et al., 2010).

In the comparison studies with model simulations the $\mathrm{CO}$ VCDs from SCIAMACHY were typically found to be higher than the corresponding model data, especially over polluted regions. This finding is in agreement with recent studies suggesting that current emission inventories underestimate the true emissions (e.g., Gloudemans et al., 2006; de Laat et al., 2006, 2007, 2010; Gloudemans et al., 2009; Kopacz et al., 2010). However, most studies indicated that the comparisons between SCIAMACHY observations and those from other satellite instrument suffer from two general problems:

(a) For many of the comparisons no exact quantitative agreement could be expected (e.g., Buchwitz et al., 2004, 2006a, 2007; Gloudemans et al., 2005; Straume et al., 2005), because they were affected by the different spatio-temporal sampling of SCIAMACHY and other satellite observations: Besides different height sensitivities of near-IR and thermal IR sensors often also not strictly collocated observations were compared. For example, even night-time observations of the thermal IR sensors were included in the comparison, whereas SCIAMACHY and other VIS instruments only make daytime observations. Also, the effect of clouds on the SCIAMACHY observations was considered in different ways: often simply observations above a certain cloud fraction threshold were skipped. Nevertheless, in general a good agreement of the observed patterns was found.

(b) Some comparison studies were performed in a quantitative way (e.g., Turquety et al., 2008; Tangborn et al., 2009; de Laat et al., 2010; Kopacz et al., 2010): Only collocated observations were used for these comparisons and the different height-dependencies of near IR and thermal IR sensors were adequately considered (e.g., using model simulations as transfer tools). In particular Turquety et al. (2008) retrieved a boundary layer partial CO VCD from the comparison of SCIAMACHY and MOPITT observations, and related these partial CO VCDs to the respective quantity from the model simulations. However, in these comparisons often inconsistencies between the satellite sensors and/or model results were found, limiting the quantitative interpretation of the retrieved results. Besides possible errors of the MOPITT observations and/or the model simulations, these biases can be related to SCIAMACHY $\mathrm{CO}$ retrievals.

In this study we implemented two important improvements to the IMAP CO retrieval algorithm. First, in order to correct for the remaining biases of the SCIAMACHY CO VCDs, we apply a normalisation procedure based on simultaneous MOPITT observations over the oceans. In addition, a quantitative cloud correction scheme was applied to the SCIAMACHY CO VCDs. Both correction schemes are described in detail below. We then compare the resulting SCIAMACHY CO data set for the years 2004 and 2005 to results from three global atmospheric chemistry models: MATCH (Model of Atmospheric Transport and Chemistry, Max-Planck-Institute for Chemistry, (von Kuhlmann et al., 2003), EMAC (ECHAM5/MESSy Atmospheric Chemistry modelling system, Max-Planck-Institute for Chemistry, Jöckel et al., 2006) and GEOS-Chem (Bey et al., 2001). In 
addition we also included MOPITT observations in this comparison. For the observations of both satellite instruments, the respective height-dependent sensitivities were explicitly considered by using the corresponding averaging kernels. Besides several regions with intense biomass burning, the comparison also includes Eastern China, where particularly high $\mathrm{CO}$ concentrations from anthropogenic emissions occur.

The paper is organized as follows: in Sect. 2 the SCIAMACHY instrument and data analysis are presented. Particular emphasis is put on the systematic bias of the CO VCD retrieved from SCIAMACHY. Section 3 presents the details of the normalisation procedure using MOPITT observations over the oceans. In Sect. 4 our cloud correction procedure for the SCIAMACHY observations is described and results of validation studies using ground based FTIR measurements are shown. Section 5 presents the comparison of the cloud corrected CO VCDs with MOPITT observations over the continents. In Sect. 6 the different atmospheric models are introduced, and in Sect. 7 the comparison between the satellite data sets and model results is presented. Section 8 summarises the main findings of our study.

\section{SCIAMACHY instrument and data analysis}

\subsection{SCIAMACHY instrument}

In 2002 SCIAMACHY was launched on board of ENVISAT (Burrows et al., 1995; Bovensmann et al., 1999). SCIAMACHY consists of a set of eight spectrometers that simultaneously measure sunlight reflected from the Earth's atmosphere and from the ground in eight spectral windows covering the wavelength range between $240 \mathrm{~nm}$ and $2380 \mathrm{~nm}$ with moderate spectral resolution $(0.2-1.2 \mathrm{~nm}$ full width at half maximum, FWHM). The satellite operates in a nearly polar, sun-synchronous orbit at an altitude of about $800 \mathrm{~km}$ with a local equator crossing time at approximately 10:00 a.m. While the satellite orbits in an almost north-south direction, the SCIAMACHY instrument scans the surface across track (i.e. east-west direction) during daytime. It operates in different viewing modes (nadir, limb, and occultation). In the standard operation mode, alternating limb and nadir measurements are performed. For the CO retrieval, we only use nadir spectra and the typical ground pixel size is $30 \mathrm{~km}$ (along track) times $120 \mathrm{~km}$ (across track). Due to this rather coarse spatial resolution, the probability for cloud contamination is rather high (Krijger et al., 2007). Global coverage is achieved after 6 days at the equator. At higher latitudes better coverage is achieved because of the partial overlap of neighboring orbits.

\subsection{CO analysis}

In contrast to the UV/Vis spectral region, the near IR spectral range exhibits peculiarities that render classical DOAS algorithms for $\mathrm{CO}$ retrieval unsuitable: first, there is a strong sensitivity to temperature and pressure of the narrow near IR absorption lines. Absorptions are very strong and lines not fully resolved by the spectral resolution of the instrument, rendering the retrieval nonlinear. Second, the weak CO absorptions are overlapped by strong methane and water vapor lines whose interferences are stronger than the $\mathrm{CO}$ absorption itself. Buchwitz et al. (2000) were the first to focus on the near infrared and introduced the concept of Weighting Function Modified (WFM) - DOAS. To account for the general non-linearity of the problem and to avoid interferences between strong absorbers, a new Iterative Maximum A Posteriori DOAS (IMAP-DOAS) algorithm was developed (Frankenberg et al., 2005a). The algorithm is based on optimal estimation theory introduced to the remote sensing community by Rodgers (1976). This method directly iterates the vertical column densities of the absorbers of interest until the expected spectral signature of the total optical density fits the measurement. The a-priori profiles for the IMAP algorithm are constructed according to the US standard atmosphere. Since the observation in the near IR is sensitive to the whole atmospheric column, the selection of the $\mathrm{CO}$ a-priori profile has only negligible influence on the retrieved CO VCD (Frankenberg et al., 2005a,b). The IMAP algorithms accounts for non-linearities due to spectrally nonresolved strong absorptions and considers the sensitivity to pressure and temperature changes in the atmospheric profile. This algorithm minimizes systematic biases that would occur in classical DOAS algorithms. A detailed description of the algorithm can be found in Frankenberg et al. (2005a). Other research groups also developed modified algorithms for the near infrared spectral region (e.g., Schrijver, 2004; Buchwitz et al., 2004; Gloudemans et al., 2005).

The output of the IMAP retrieval is the total atmospheric $\mathrm{CO}$ vertical column density (VCD), i.e. the vertically integrated $\mathrm{CO}$ concentration. It is retrieved under the implicit assumption of a geometric air mass factor. The air mass factor (AMF) defines the ratio between the so called slant column density ( $\mathrm{SCD}$, the concentration integrated along the atmospheric light path) and the VCD (see e.g., Solomon et al., 1987)

$\mathrm{AMF}=\mathrm{SCD} / \mathrm{VCD}$.

In simple cases (e.g., if atmospheric scattering can be neglected), a geometric AMF can be used, which is defined as follows:

$\mathrm{AMF}_{\text {geo }}=1 / \cos (\mathrm{LOS})+1 / \cos (\mathrm{SZA})$

with LOS the viewing angle with respect to the nadir and SZA the solar zenith angle. AMFs can be calculated for the total atmospheric columns or also for partial columns according to selected height layers. AMFs for selected height layers are often referred to as box-AMFs:

$\mathrm{AMF}_{\mathrm{box}}\left(z_{i}\right)=\operatorname{SCD}\left(z_{i}\right) / \operatorname{VCD}\left(z_{i}\right)$ 
with $\operatorname{SCD}\left(z_{i}\right)$ and $\operatorname{VCD}\left(z_{i}\right)$ being the partial slant and vertical column densities of layer $i$.

\subsection{Problems of the SCIAMACHY CO retrievals and possible correction procedures}

In many studies by different groups, biases of the SCIAMACHY CO VCDs were reported or were obvious in the presented data sets (in Fig. 1 an example from our SCIAMACHY CO retrieval is shown). Typically, they not only depend on location (e.g. showing a latitudinal gradient) but also vary with time (Buchwitz et al., 2005, 2007; Dils et al., 2006a; Turquety et al., 2008; Gloudemans et al., 2009; Tangborn et al., 2007; Kopacz et al., 2010; de Laat et al., 2010). The reasons for these biases are not completely understood, but are probably related to several problems of the SCIAMACHY detectors or retrieval algorithms. Most importantly, a changing ice-layer on the SCIAMACHY near-IR detectors influences the measurements in several ways (e.g., Gloudemans et al., 2005). After decontamination periods, this ice layer builds up in time, causing a time-dependent loss of signal and change of the instrument slit function. In addition, the dark current of the detectors is influenced. Variations of the dark current occur also within individual orbits. The SCIAMACHY near-IR detectors also suffer from a variable but generally increasing number of so called bad and dead pixels, which can not be used for the analysis. For all of these problems sophisticated solutions have been developed and applied in recent years (e.g., Gloudemans et al., 2005; Frankenberg et al., 2005b; Buchwitz et al., 2006a, 2007; Gloudemans et al., 2009). Nevertheless, these corrections are still not perfect, and the retrieved CO VCDs are subject to remaining errors. It was shown that the application of different dead/bad pixel masks leads to systematic changes of the retrieved CO VCDs (Buchwitz et al., 2007).

In addition to the systematic errors caused by these effects, also the random errors for the $\mathrm{CO}$ retrieval are generally large (up to $>100 \%$ ), mainly depending on the brightness of the observed scene (Gloudemans et al., 2005, 2008; Frankenberg et al., 2005a; Buchwitz et al., 2006a; de Laat et al., 2007). Thus many individual observations are usually averaged (for example monthly means), reducing statistical errors.

Besides these instrumental problems, some ambiguity with respect to the analysis parameters remains. For example, the specific choice of the spectral window (Gloudemans et al., 2005; Buchwitz et al., 2006a) and the spectral data used for the analysis has an influence on the retrieved CO VCDs (Gloudemans et al., 2005, 2009). These effects are mainly related to the fact that the strength of the overlapping absorptions of $\mathrm{CH}_{4}$ and $\mathrm{H}_{2} \mathrm{O}$ are much stronger than that of $\mathrm{CO}$. Another problem is that usually a height-independent sensitivity for the SCIAMACHY CO observations was assumed. While this is mostly true for completely cloud-free conditions and small solar zenith angles (Buchwitz et al., 2004;
Gloudemans et al., 2008; de Laat et al., 2010), the sensitivity of SCIAMACHY for the lowest atmospheric layers can be systematically reduced for large solar zenith angles and/or in the presence of clouds (see below).

Like the other groups working on the SCIAMACHY CO retrieval, we also investigated several ways to correct and minimise the effects of the instrumental problems and limitations of the spectral analysis. For example we quantified the instrumental slit function from the shape and the width of the strong absorption lines of $\mathrm{CH}_{4}$ and $\mathrm{H}_{2} \mathrm{O}$ close to the $\mathrm{CO}$ fitting range from the measured spectra on a daily basis. We then applied the resulting time dependent slit function to our $\mathrm{CO}$ retrieval. In a similar way we determined and corrected a possible time-dependent spectral offset (e.g., Gloudemans et al., 2005). Furthermore, we applied the normalisation procedure using the simultaneously retrieved $\mathrm{CH}_{4} \mathrm{VCD}$. As can be seen in Fig. A1 in the appendix, the retrieved $\mathrm{CH}_{4} \mathrm{VCD}$ shows very similar temporal varying biases. Thus Buchwitz et al. (2007) introduced a correction procedure using the retrieved $\mathrm{CH}_{4} \mathrm{VCD}$ for the correction of the CO VCDs. However, although the consistency of the CO VCDs was substantially improved by this procedure, still biases remained. The results of the different correction procedures for the $\mathrm{CO} V \mathrm{VD}$ are described in detail in Liu (2010). However, it turned out that (similar to the results of other groups), part of the problems of the SCIAMACHY CO data could be improved, at least for limited periods of time, but systematic biases still remained. Here it is interesting to note that the improvement reported by other studies (e.g. Gloudemans et al., 2005) is better than found in our study. The reason for these differences are not clear, but might be caused by the use of different retrieval settings.

From the temporal variation and latitudinal dependence of the biases of the SCIAMACHY CO VCDs it can be concluded that they are complex functions of probably several parameters (e.g., solar zenith angle, cloud properties, number and location of bad and dead detector pixels, instrument throughput, and strength of $\mathrm{H}_{2} \mathrm{O}$ and $\mathrm{CH}_{4}$ absorptions). Besides the comparison between SCIAMACHY with other satellite sensors, also comparisons of SCIAMACHY data with model results will be systematically influenced by these biases in the SCIAMACHY CO VCDs.

For these reasons, we developed a normalisation procedure of SCIAMACHY CO VCDs using simultaneous observations of the MOPITT instrument (see e.g., Drummond and Mand, 1996; Deeter et al., 2003) over the ocean. This normalisation is performed on a daily basis and depending on latitude (the details are presented in Sect. 3). Thus, especially the spatio-temporal variation of the bias between SCIAMACHY and MOPITT is corrected. Of course, due to this normalisation procedure the SCIAMACHY CO data can not be regarded as an independent data set. In particular, all potential biases of the MOPITT observations will be directly transferred to the retrieved SCIAMACHY CO VCDs. However, MOPITT observations have been validated 


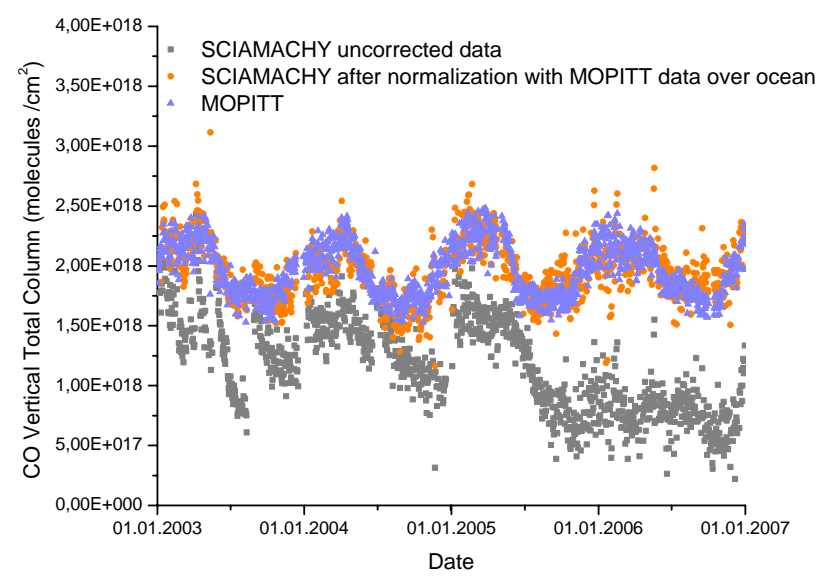

Fig. 1. Comparison between MOPITT CO VCDs and SCIAMACHY CO VCDs averaged over Sahara $\left(20^{\circ} \mathrm{N}\right.$ to $28^{\circ} \mathrm{N} ; 8^{\circ} \mathrm{W}$ to $28^{\circ} \mathrm{E}$ ) for each day in the period 2003 to 2006 with and without applying MOPITT normalization to the SCIAMACHY CO VCDs. The jumps of the uncorrected data in 2003 and 2004 are related to several ice decontamination phases. The reason for the drop in summer 2005 is not completely clear, but might be related to a broadening of the effective slit function (Liu, 2010).

in many studies. While MOPITT version 3 data showed substantial and temporally varying biases (e.g. Emmons et al., 2004, 2009), the most recent version 4, which is used in this paper, shows much smaller biases and almost now temporal drift (Deeter et al., 2010). Using our procedure any systematic (and varying) biases between both instruments are largely reduced and subsequently the potential of the different height sensitivities of both instruments can be fully explored.

In addition to the normalisation procedure, we also applied a sophisticated cloud correction. Thus far, the cloud effect was discussed in many studies, but it was - to our knowledge - not explicitly corrected for.

Instead, usually only measurements for small cloud fractions (typically $<20 \%$ ) are considered (e.g., de Laat et al., 2010; Kopacz et al., 2010, and references therein). Using such a rather strict selection criterion leads to a strong decrease of the number of useful SCIAMACHY observations. According to a study of Krijger et al. (2007) only about $25 \%$ of all SCIAMACHY CO observations have a cloud fraction $<20 \%$. Thus e.g., during one month on average only $1.5 \mathrm{CO}$ observations at a given location can be used if this selection criterion is applied.

As already stated in several studies (e.g., Buchwitz et al., 2004, 2005; Frankenberg et al., 2005a; Gloudemans et al., 2006; de Laat et al., 2007), clouds can lead to a systematic underestimation of the true CO VCDs, because the part of the $\mathrm{CO}$ profile below the cloud is shielded. This underestimation becomes especially large for observations over polluted re- gions (where enhanced $\mathrm{CO}$ concentrations occur close to the surface) and/or for high clouds (see Fig. A3 in the appendix). Even for small cloud fractions the cloud effect can be substantial, because usually (exceptions include deserts and ice surfaces) clouds are much brighter than the surface, and the signal from the clouded part usually dominates the measured spectra. As it will be shown later, even for small cloud fractions the related systematic errors can be large (e.g., up to $100 \%$ for observations with cloud fraction $<20 \%$ over polluted regions).

It should be noted that in many cases the systematic cloud effect is further enhanced if the SCIAMACHY observations are averaged weighting by the inverse of the retrieval error (e.g., de Laat et al., 2006). Since the retrieval error increases with decreasing brightness of the observed scene, measurements with higher cloud fractions will be systematically weighted more heavily, and any systematic cloud effect will thus be further increased.

Buchwitz et al. (2007) have introduced an implicit cloud correction using a normalisation based on simultaneously retrieved $\mathrm{CH}_{4}$ VCDs. However, because of the different height profiles of $\mathrm{CO}$ and $\mathrm{CH}_{4}$ (and probably also because of other differences like the absorption strength), this method can not completely correct for the influence of clouds. Especially in regions with strong $\mathrm{CO}$ emissions, the height profiles of $\mathrm{CO}$ and $\mathrm{CH}_{4}$ are particularly different leading to a systematic underestimation of the true CO VCD. Buchwitz et al. (2007) also state that while many retrieval problems are largely improved by the $\mathrm{CH}_{4}$ normalisation procedure, still some systematic effects of the retrieved CO VCD remain.

In this study, we apply an explicit cloud correction for the retrieval of CO VCDs from SCIAMACHY. It is based on results of the FRESCO+ algorithm (Fast REtrieval Scheme for Cloud from the Oxygen A band, see Koelemeijer et al., 2001) and takes into account the (effective) cloud fraction and cloud top height. Besides the correction of the cloud effect, our algorithm also provides height dependent averaging kernels for the individual SCIAMCHY CO measurements. Details of the cloud correction procedure are given in Sect. 4 .

After the normalisation of the SCIAMACHY CO VCDs and the cloud correction, our $\mathrm{CO}$ data set is well suited to be compared in a quantitative way with the results of model simulations.

From the spectral retrieval, also the uncertainty of the derived CO VCD is determined. Typically, for individual measurements, these errors are dominated by the limited signal to noise ratio (see e.g. Gloudemans et al., 2006). Here it is interesting to note that especially the comparison with model results indicates that the true random error is probably substantially smaller than the noise error derived from the spectral retrieval. 


\section{Normalisation using MOPITT data over the oceans}

The initial comparison between MOPITT and SCIAMACHY indicated that the difference between the $\mathrm{CO}$ VCDs measured by both instruments depends on latitude and time (probably related to changes in SZA and relative azimuth angle). Thus, no simple correction of the SCIAMACHY CO column densities (e.g., by adding a constant or time-dependent offset) is possible, and we decided to apply a latitudinally and seasonally dependent correction of the offset in the SCIAMACHY CO VCDs using MOPITT observations over the oceans. For that purpose we used MOPITT version 4 data obtained from the NASA Langley Research Center Atmospheric Science Data Center (http://eosweb.larc. nasa.gov/PRODOCS/mopitt/table_mopitt.html).

The main justification of such a normalisation procedure is that all strong $\mathrm{CO}$ emissions are located over land and thus the $\mathrm{CO}$ distribution over the remote ocean (excluding outflow regions) can be expected to be relatively well mixed. In particular, in the lowest atmospheric layers away from the continents no strong spatial gradients of the $\mathrm{CO}$ concentration are expected. Thus, in spite of the low sensitivity of the MOPITT instruments for near-surface layers, CO VCDs retrieved from both sensors should show good agreement, if the a priori assumptions in the MOPITT retrieval for the $\mathrm{CO}$ concentration in the lowest atmospheric layers are reasonable. Over oceans, far away from strong CO sources, this prerequisite should in general be fulfilled. For the comparison with MOPITT observations we selected SCIAMACHY observations above low-lying clouds (cloud top heights between 0 and $2 \mathrm{~km}$ and effective cloud fractions $>20 \%$ ), for which the SCIAMACHY observations have a similar heightdependent sensitivity compared to MOPITT. The cloud properties are derived from the FRESCO+ algorithm, see Koelemeijer et al. (2001) and Wang et al. (2008). The height dependent averaging kernels of the individual SCIAMACHY observations (see Sect. 4) are applied to the coincident MOPITT measurements over the oceans before both data sets are compared. Thus, even if the true $\mathrm{CO}$ concentration in the low atmosphere differs from the MOPITT a priori values, this should only have a small effect on the comparison. We estimate the remaining errors affecting the comparison of the CO VCD to be $<5 \%$ for unperturbed profiles. In cases of effective transport of polluted air masses over the ocean the corresponding error might be larger.

For the normalization procedure, we divided the remote ocean area into 15 latitude bins from north to south (see Fig. 2). We calculated offsets $\Delta \mathrm{CO}_{\text {lat }}$ between SCIAMACHY and MOPITT VCDs for these regions on a daily basis according to the following equation:

$$
\Delta \mathrm{CO}\left(\text { lat }_{i}\right)=\overline{\mathrm{CO}}_{\text {MOPPIT, above cloud height }}\left(\text { lat }_{i}\right)-\overline{\mathrm{CO}}_{\mathrm{SCIA}}\left(\text { lat }_{i}\right) \text { (4) }
$$

Here $\overline{\mathrm{CO}}_{\text {SCIA }}\left(\right.$ lat $\left._{i}\right)$ indicates the mean value of all SCIAMACHY CO VCDs within the selected latitude bin which fulfil the cloud selection criteria (cloud fraction $>20 \%$, cloud top height $<2 \mathrm{~km}$ ). $\overline{\mathrm{CO}}_{\text {MOPPIT, above cloud height }}\left(\mathrm{lat}_{i}\right)$ indicates the mean value of all MOPITT partial CO VCDs above the average cloud top height of the SCIA observations within the selected latitude bin. The offset $\triangle C O$ (lat $\left._{i}\right)$ is determined on a daily basis and interpolated (using splines) to a latitudinal grid of $1^{\circ}$.

Assuming that the CO VCDs measured by MOPPIT over remote ocean area are correct and that the bias of the SCIAMACHY CO VCD does not depend on longitude, the determined offset between MOPPIT and SCIAMACHY $\triangle \mathrm{CO}\left(\mathrm{lat}_{i}\right)$ can be used for the correction of the SCIAMACHY CO observations on a global scale.

In order to verify our normalization process we compared MOPPIT CO VCDs and SCIAMACHY CO VCDs over the continents; in Fig. 1 the results over the Sahara are shown (additional comparisons are shown in Sect. 5). As expected, after the normalization procedure, the agreement between the MOPITT and SCIAMACHY data is strongly improved.

Here it might be interesting to note that de Laat et al. (2010) reported on a positive bias of MOPITT over desert regions (see also George et al. 2009). However, this bias seems to be reduced in MOPITT version 4 data, especially in months without strong biomass burning. It is also smaller in the latitude band used here $\left(20^{\circ} \mathrm{N}-28^{\circ} \mathrm{N}\right)$ than in the region investigated by de Laat et al. (2010). Good agreement between SCIAMACHY and MOPITT (version 3) CO data over Sahara were also reported by Buchwitz et al. (2007). From the comparison between model results and MOPITT observations (Sect. 7), it seems that in most seasons MOPITT CO VCDs over the Sahara still show a positive bias. However, this should have no important impact on the results of this study, because (a) we use only MOPITT observations over the oceans for the normalisation procedure and (b) we are not focussing on the results over the Sahara.

In Fig. 3 the global maps of the annual mean SCIAMACHY CO VCDs for four years (2003-2006) for different stages of the normalisation and cloud correction are shown. The top panel shows non-corrected results, the middle panel shows the same results after normalization with MOPITT data over the oceans. The bottom panel shows the same results after an additional cloud correction was applied (see Sect. 4). While the absolute values of the CO VCDs change after each processing step, the spatial patterns only slightly change (see also the difference maps in Fig. A2 of the appendix). This indicates that the spatial patterns of the SCIAMACHY CO VCD are almost independent from the normalisation with MOPITT data (and also from the cloud correction). After the normalization and cloud correction, the absolute values in different years become similar indicating that existing biases are largely reduced. However, the results for the year 2006 show some deviations from the other years probably indicating the limitations of our normalization procedure. 


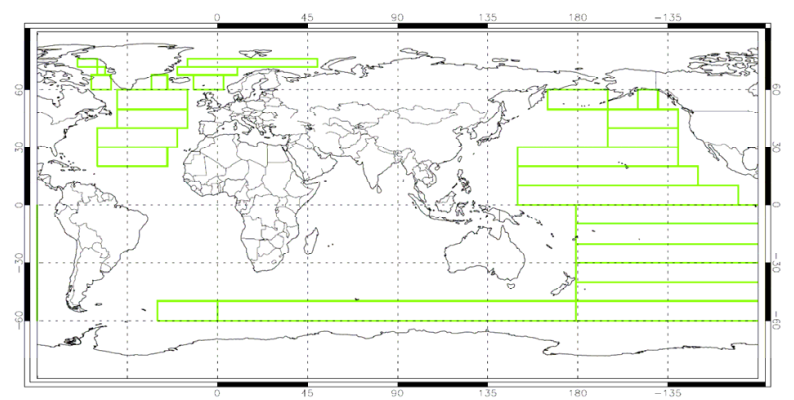

Fig. 2. Latitude bins selected over the remote ocean for the normalization procedure of SCIAMACHY CO VCDs using MOPITT data (see Sect. 3).

It should be noted that the SCIAMACHY CO VCDs normalized in this way can not be considered as independent data. In particular, its accuracy depends critically on the accuracy of the MOPITT data: systematic errors of the MOPITT data will almost directly result in similar errors of the normalized SCIAMACHY data set. Here it should be noted that extensive validation of the MOPITT CO data has been performed by Deeter et al. (2010), using a variety of in situ aircraft data. They found biases in the MOPITT data of less than $6 \%$ for different altitude levels. The normalized SCIAMACHY CO data are particular useful, since observations in the near IR are sensitive to the total atmospheric CO VCD, SCIAMACHY data can yield important information on the location and strength of local emission sources. Here in particular the comparison of CO VCDs from SCIAMACHY (and also MOPITT) over continental sources with model data is of great interest (see Sect. 7).

\section{Cloud correction algorithm}

Before the normalised SCIAMACHY data set can be used for comparison with other data sets such as model results, the effect of clouds on the measurement sensitivity has to be corrected. Cloud effects can be minimised by excluding measurements with large effective cloud fractions; for satellite observations of tropospheric trace gases often a threshold of $10 \%$ to $30 \%$ effective cloud fractions is used. In our study we consider measurements with effective cloud fractions $<20 \%$.

Although these cloud fractions are rather small, the remaining clouds can still strongly affect the retrieved $\mathrm{CO}$ VCDs, especially if the cloud altitude is high, the surface albedo is low, and the near-surface $\mathrm{CO}$ concentration is high. Examples of the shielding effect of clouds for small cloud fractions are shown in Fig. A3 in the appendix. An appropriate cloud correction is particularly important for measurements close to strong emission sources. We considered the influence of the actual effective cloud fraction and ef-

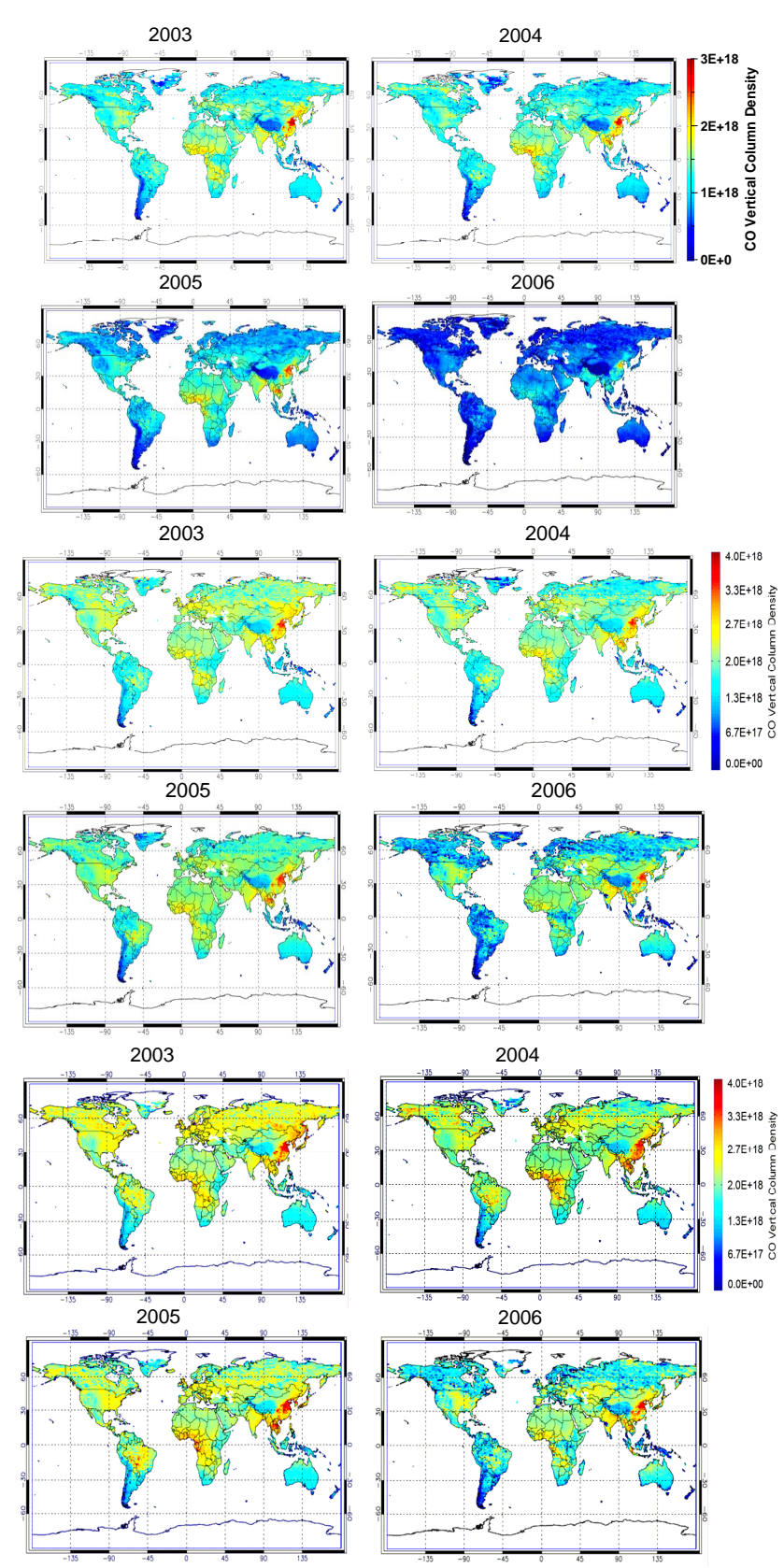

Fig. 3. Global annual mean $\mathrm{CO}$ distribution for uncorrected data (top), after normalization with MOPITT (center) and after additional cloud correction (bottom). Note the different colour scales. The differences between results for the different correction steps are shown in the appendix (Fig. A2).

fective cloud top height using simultaneously retrieved cloud properties from the FRESCO+ algorithm (Koelemeijer et al., 2001; Wang et al., 2008). For the cloud top albedo we assumed a value of $40 \%$, which is about half of the value at $760 \mathrm{~nm}$ (see e.g., Nakajima and King, 1990), at which the FRESCO+ cloud algorithm is applied. 


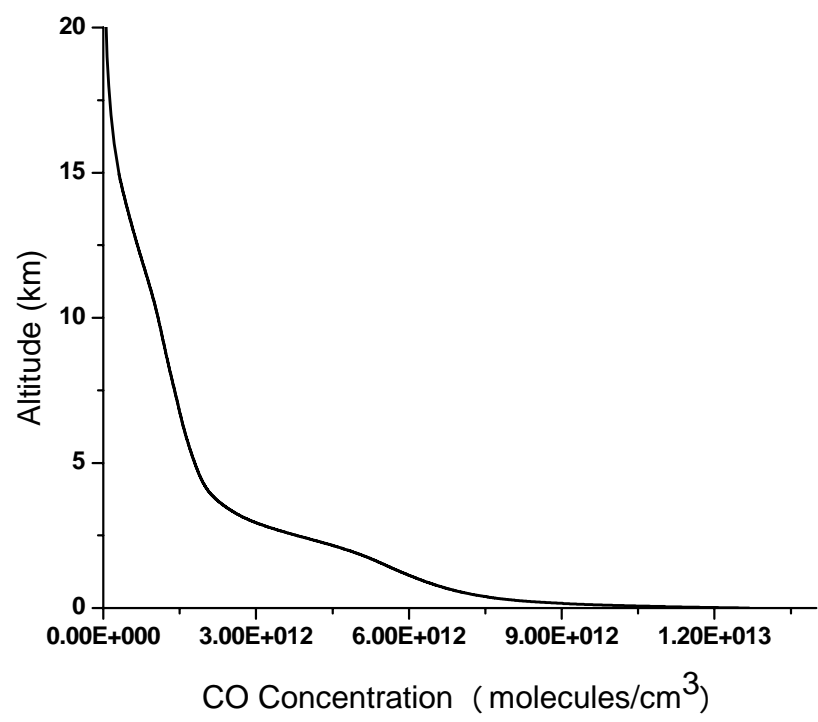

Fig. 4. Standard CO profile assumed for the calculation of the SCIAMACHY total CO column density standard data set.

The influence of the surface albedo was taken into account using albedo maps (yearly average) from the Moderate Resolution Imaging Spectroradiometer (MODIS) for the wavelength range of our CO retrieval (Justice et al., 1998). In principle, also seasonally varying surface albedo could be used here, but the effect of the seasonal variation of the surface albedo on the retrieved SCIAMACHY CO VCDs is typically below $1 \%$, and at maximum $5 \%$. Thus we decided not to explicitly include the seasonal variation of the surface albedo in our cloud correction procedure.

In our cloud correction routine we use the independent pixel approximation: the $\mathrm{CO}$ absorptions of the clear and cloudy parts of a satellite pixels are weighted according to the effective cloud fraction and the respective radiances of the cloudy and clear fractions. For the cloudy part of the pixel we assume that the sensitivity is zero below the cloud top. This assumption is justified by the high effective albedo of clouds. For the clear part of the pixel we assume a constant sensitivity throughout the atmosphere, which is justified by the low probability of Rayleigh-scattering in the near IR spectral range. Note that we chose the description of the clouds by a so called Lambertian reflector, because such a cloud model is also used in the FRESCO+ algorithm.

First, box-AMFs (see Eq. 3) for different layer heights are calculated:

$\mathrm{AMF}_{\text {box }}\left(z_{i}\right)=\frac{(1-\mathrm{CF}) \cdot \mathrm{SA} \cdot \mathrm{AMF}_{\mathrm{Clear}}+\mathrm{CF} \cdot \mathrm{CA} \cdot \mathrm{AMF}_{\mathrm{Cloud}}}{(1-\mathrm{CF}) \cdot \mathrm{SA}+\mathrm{CF} \cdot \mathrm{CA}}$

Here $z_{i}$ indicates the height of the atmospheric layer, $\mathrm{CF}$ the (effective) cloud fraction, SA the surface albedo, and CA the cloud top albedo. $\mathrm{AMF}_{\text {clear }}$ is approximated by the geometrical AMF assumption (Eq. 2). $\mathrm{AMF}_{\text {cloud }}$ is set to zero for $\mathrm{z}_{i}<$ the cloud top height and set to the geometric AMF for $z_{i} \geq$ the cloud top height.

These box-AMFs describe the height resolved sensitivity of the SCIAMACHY observations depending on the actual effective cloud fraction, cloud top height, and ground albedo. If the (relative) $\mathrm{CO}$ profile for the observed atmospheric scene is known (or assumed), the total cloud-corrected $\mathrm{CO}$ VCD can then be calculated from the SCIAMACHY observation based on the height dependent sensitivity:

$\mathrm{VCD}_{\text {SCIA }, \text { corrected }}=\frac{\mathrm{VCD}_{\text {SCIA }} \cdot \mathrm{AMF}_{\text {geo }}}{\mathrm{AMF}_{\text {total }, \text { profile }}}$

with

$\mathrm{AMF}_{\text {total,profile }}=\frac{\sum_{i} \mathrm{AMF}_{\mathrm{box}}\left(z_{i}\right) \cdot c_{\mathrm{CO}, \text { profile }}\left(z_{i}\right)}{\sum_{i} c_{\mathrm{CO}, \text { profile }}\left(z_{i}\right)}$

$\mathrm{VCD}_{\text {SCIA }}$ indicates the IMAP CO VCD after the normalisation procedure, see $\operatorname{Sect.~3;} \mathrm{c}_{\mathrm{CO}}$, profile $\left(z_{i}\right)$ indicates the $\mathrm{CO}$ concentration at layer $i$.

Using the formalism of Eskes and Boersma (2003), besides the cloud-corrected CO VCDs, also averaging kernels can be calculated for individual SCIAMACHY CO observations.

$\mathrm{AK}\left(z_{i}\right)=\frac{\operatorname{AMF}_{\text {box }}\left(z_{i}\right)}{\mathrm{AMF}_{\text {total }, \text { profile }}}$

If no independent information on the $\mathrm{CO}$ profile (e.g., from model simulations) is available, we used a "standard CO profile" for the retrieval of CO VCDs from SCIAMACHY observations. This "standard profile" is constructed as a compromise between CO profiles from chemical models for polluted and remote areas; it is shown in Fig. 4. Using this profile as input in Eq. (7), we determine our new standard SCIAMACHY CO VCD:

$\mathrm{VCD}_{\text {SCIA }, \text { standard }}=\frac{\mathrm{VCD}_{\text {SCIA }} \cdot \mathrm{AMF}_{\text {geo }}}{\mathrm{AMF}_{\text {total }, \text { standard }}}$

It is interesting to note that the AMF for the standard profile only depends on the relative shape of the $\mathrm{CO}$ profile, since in the chosen wavelength range $\mathrm{CO}$ is a relatively weak atmospheric absorber with OD $\ll 1$. Of course, this choice of a $\mathrm{CO}$ profile is arbitrary and can lead to large deviations of the retrieved CO VCDs from the true atmospheric CO VCDs depending on the deviation of relative profile shape of the assumed standard profile from the true atmospheric $\mathrm{CO}$ profile: close to emission sources, where the $\mathrm{CO}$ concentration in the near-surface layers are typically enhanced (relative to the standard profile), the retrieved SCIAMACHY CO VCD tends to underestimate the true $\mathrm{CO}$ VCD. In contrast, for remote unpolluted regions, the actual surface-near $\mathrm{CO}$ concentration might be decreased (relative to the standard profile), and thus the retrieved SCIAMACHY CO VCD tends to overestimate the true CO VCD. These dependencies should 

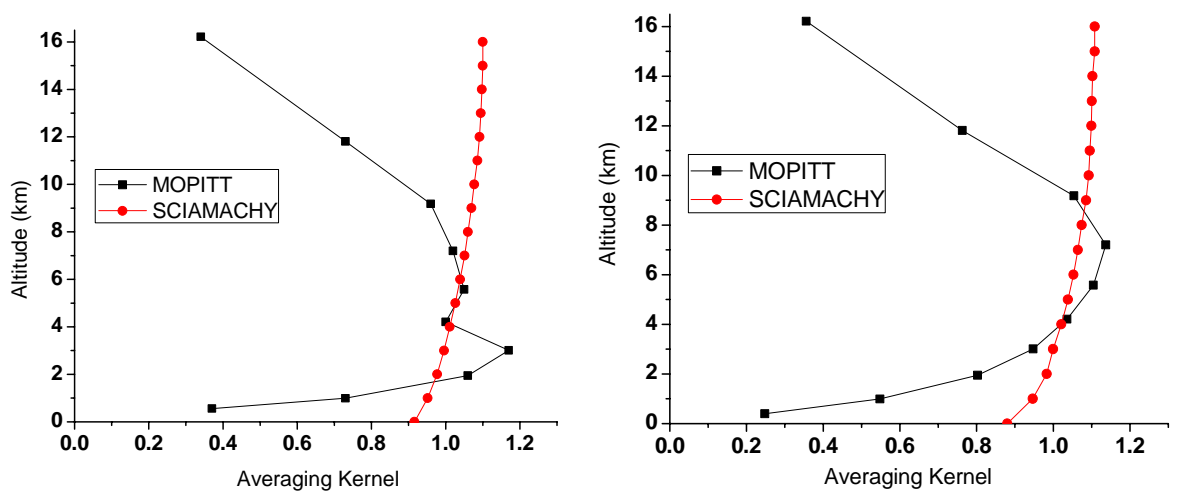

Fig. 5. Examples of MOPITT's and SCIAMACHY's monthly mean averaging kernels over central Africa (left, $5^{\circ} \mathrm{N}$ to $12^{\circ} \mathrm{N} ; 15^{\circ} \mathrm{W}$ to $32^{\circ} \mathrm{E}$, January 2004) and East China (right, $20^{\circ} \mathrm{N}$ to $40^{\circ} \mathrm{N} ; 107^{\circ} \mathrm{E}$ to $123^{\circ} \mathrm{E}$, May 2004). Only observations with effective cloud fraction $<20 \%$ are selected.

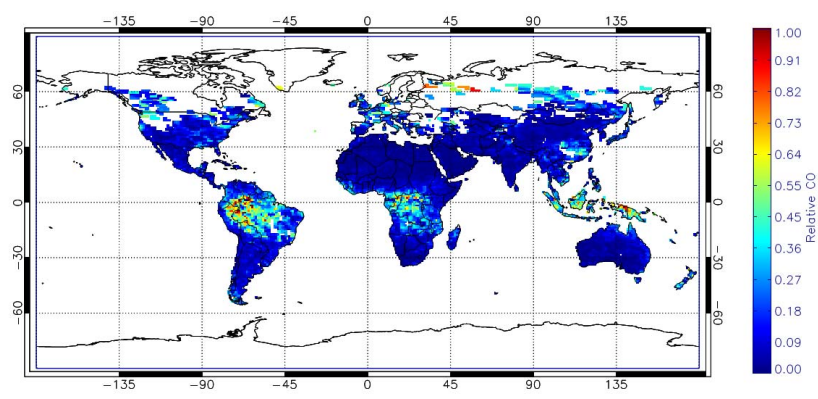

Fig. 6. Relative difference $\left[\left(\mathrm{VCD}_{\text {corrected }}-\mathrm{VCD}_{\text {uncorrected }}\right) / \mathrm{VCD}\right.$ uncorrected] of SCIAMACHY CO column densities with and without cloud correction (January 2004). Especially over regions with high cloud top heights the neglect of the cloud correction can lead to large errors even for rather small cloud fractions (here only observations with effective cloud fraction $<20 \%$ are considered; white areas indicate missing values).

be kept in mind when the values of our SCIAMACHY standard CO VCD are compared to other data sets of CO VCDs. However, if the SCIAMACHY CO VCDs are compared to data sets which provide explicit profile information (e.g., atmospheric models), the application of the averaging kernels will properly take into account the height dependent sensitivity of the SCIAMACHY observation; or in other words: if both measurements and model simulations are correct, exact agreement between both data sets must be expected after properly considering the averaging kernels of the measurements.

In addition to clouds, aerosols also influence the atmospheric radiative transfer and can have systematic effects on the SCIAMACHY CO VCDs. Gloudemans et al. (2008) investigated the aerosol effects and found that the related errors can be up to $15 \%$. Using our cloud correction scheme should lead to a first order correction of the aerosol effects, at least for mainly scattering aerosols. This finding will be of particular importance for observations over heavily polluted regions (biomass burning regions and East China), which are the main area of interest in this study. It is, however, important to note here that in the presence of absorbing aerosols, the situation is more complex (see Leitão et al., 2010), and in extreme cases, no correction of the aerosol effects will be accomplished. However, if the absorbing properties of the aerosols are similar in the spectral range of the CO absorption and the spectral range where the cloud properties are determined, the aerosol effects are at least partly corrected.

In Fig. 5 examples for the averaging kernels of SCIAMACHY CO observations (for effective cloud fraction $<20 \%$ ) are shown. The graphs present the monthly mean averaging kernels for SCIAMACHY and MOPITT observations over selected regions (central Africa, January 2004, and East China, May 2004, see also Fig. 8). It is obvious that - as expected - SCIAMACHY is much more sensitive to near surface $\mathrm{CO}$ concentrations than MOPITT. Nevertheless, due to clouds, also the sensitivity of SCIAMACHY CO observations systematically decreases towards the ground (by about $10 \%$ for observations with cloud fractions $<20 \%$ ), but this decrease is much smaller compared to MOPITT observations. The height dependent sensitivity is explicitly considered for the quantitative comparisons with model data in this study by using the respective averaging kernels (see Sect. 7).

The importance of a proper cloud correction is illustrated in Fig. 6, where the relative difference of SCIAMACHY CO VCDs with and without cloud correction is shown. The relative difference is below $10 \%$ over desert areas where the surface albedo is high and cloud fraction is low. In general, over areas with small cloud fraction and low cloud top height, relatively small differences are found. However, over areas with high cloud top heights the relative difference can reach up to $100 \%$. Here it should be noted that most of 
No corrections

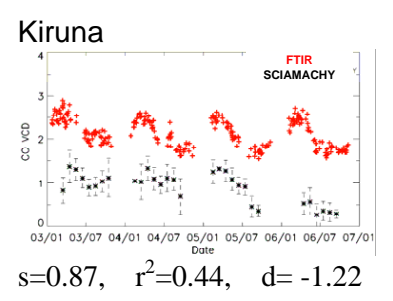

Harestua

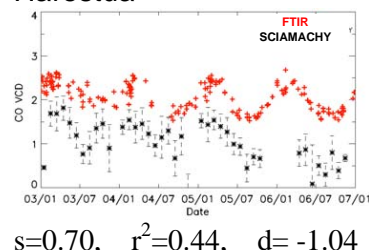

$\mathrm{s}=0.70, \quad \mathrm{r}^{2}=0.44, \quad \mathrm{~d}=-1.04$

St. Petersburg

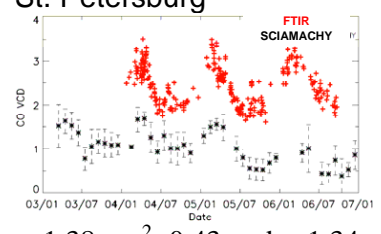

$\mathrm{s}=1.38, \quad \mathrm{r}^{2}=0.43, \quad \mathrm{~d}=-1.34$

Bremen

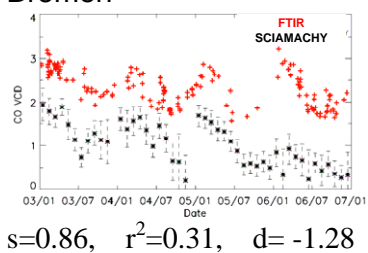

$\mathrm{s}=0.86, \quad \mathrm{r}^{2}=0.31, \quad \mathrm{~d}=-1.28$

\section{Only normalisation with \\ MOPITT}

$67.9^{\circ} \mathrm{N}, 20.2^{\circ} \mathrm{E}$

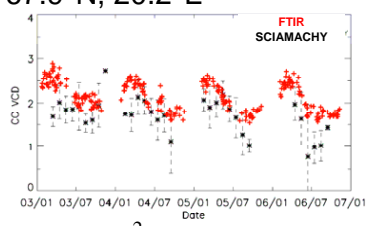

$\mathrm{s}=1.45, \quad \mathrm{r}^{2}=0.50, \quad \mathrm{~d}=-0.45$

$60.2^{\circ} \mathrm{N}, 10.8^{\circ} \mathrm{E}$
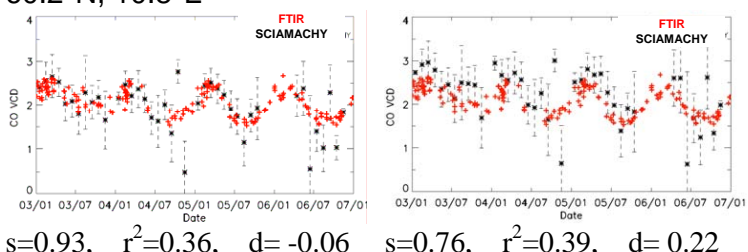

Normalisation and cloud correction

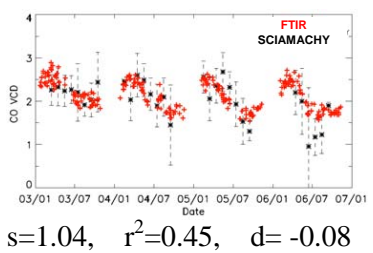

Egbert

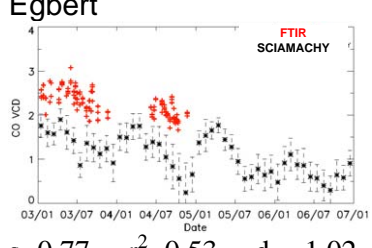

$60.0^{\circ} \mathrm{N}, 30.2^{\circ} \mathrm{E}$

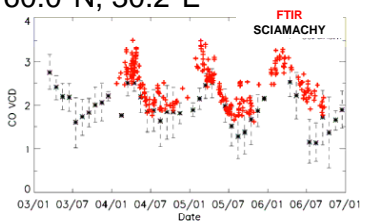

$\mathrm{s}=1.06, \quad \mathrm{r}^{2}=0.48, \quad \mathrm{~d}=-0.46$

$53.1^{\circ} \mathrm{N}, 8.7^{\circ} \mathrm{E}$
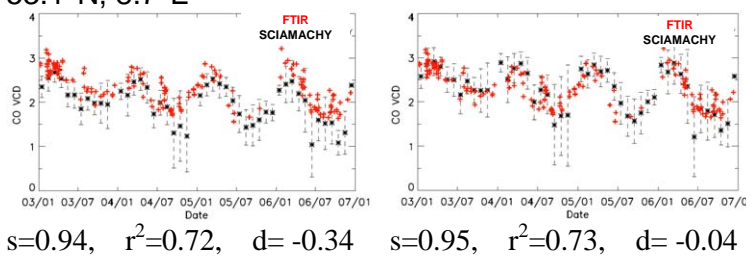

$\mathrm{s}=0.77, \quad \mathrm{r}^{2}=0.53, \quad \mathrm{~d}=-1.02$

$44.2^{\circ} \mathrm{N}, 79.8^{\circ} \mathrm{W}$

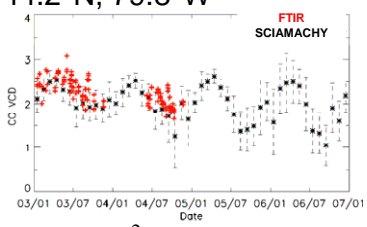

$\mathrm{s}=1.05, \quad \mathrm{r}^{2}=0.63, \quad \mathrm{~d}=-0.22$

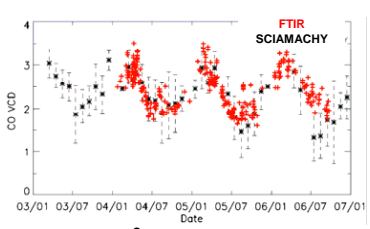

$s=1.04, \quad r^{2}=0.59, \quad d=-0.14$

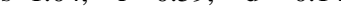

$\mathrm{s}=0.95, \quad \mathrm{r}^{2}=0.73, \quad \mathrm{~d}=-0.04$

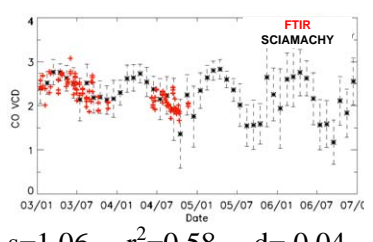

Fig. 7. Comparison of SCIAMACHY CO VCDs (black dots, monthly means) with coincident results from ground based FTIR stations. In the left part of the figure, uncorrected CO VCDs are shown; in the center part the same data are shown after normalisation with MOPITT observations (see Sect. 3); in the right part of the figure, also a cloud correction was applied (see Sect. 4). The numbers below the figures indicate the results of the correlation analyses (s: slope, $r^{2}$ : coefficient of determination) and the average difference between both data sets (d: SCIAMACHY CO VCD - FTIR CO VCD in units of $10^{18} \mathrm{molec}^{-2}$ ).

these areas (such as industrial regions and biomass burning regions) are of great interest for the test of current emission estimates.

We compared the normalised and cloud corrected SCIAMACHY CO VCDs with CO VCDs obtained by ground based FTIR measurements at different stations (Fig. 7). Besides the final product, the validation also includes the uncorrected data and the SCIAMACHY CO VCDs after the normalisation with MOPITT data over the ocean are shown. It can be clearly seen that both correction steps improve the 

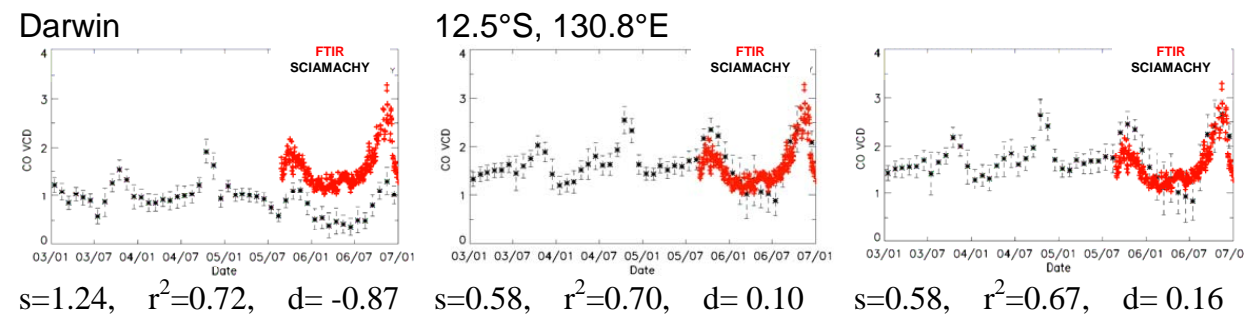

Reunion

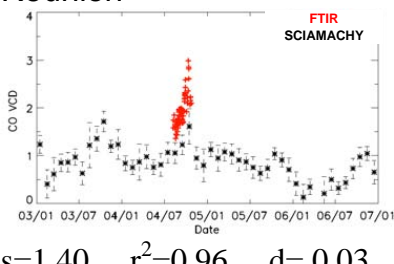

$$
\mathrm{s}=0.58, \quad \mathrm{r}^{2}=0.70, \quad \mathrm{~d}=0.10
$$

$\mathrm{s}=0.58, \quad \mathrm{r}^{2}=0.67, \quad \mathrm{~d}=0.16$

$21.1^{\circ} \mathrm{S}, 55.5^{\circ} \mathrm{E}$
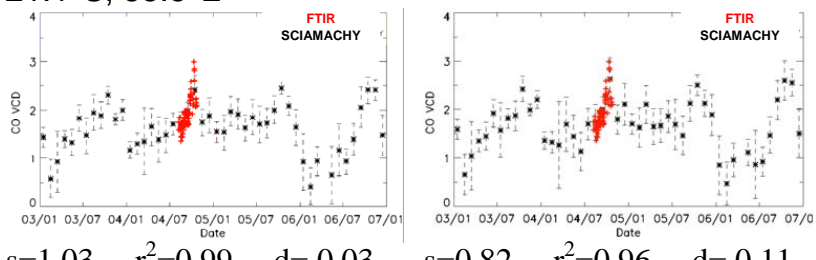

$\mathrm{s}=1.40, \quad \mathrm{r}^{2}=0.96, \quad \mathrm{~d}=0.03$

$\mathrm{s}=1.03, \quad \mathrm{r}^{2}=0.99, \quad \mathrm{~d}=0.03$

$\mathrm{s}=0.82, \quad \mathrm{r}^{2}=0.96, \quad \mathrm{~d}=0.11$

Wollongong

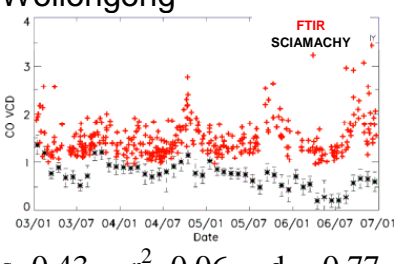

$\mathrm{s}=0.43, \quad \mathrm{r}^{2}=0.06, \quad \mathrm{~d}=-0.77$

Lauder

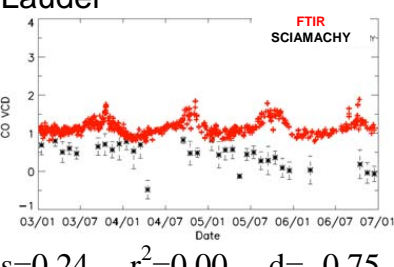

$\mathrm{s}=0.24, \quad \mathrm{r}^{2}=0.00, \quad \mathrm{~d}=-0.75$ $34.5^{\circ} \mathrm{S}, 150,9^{\circ} \mathrm{E}$
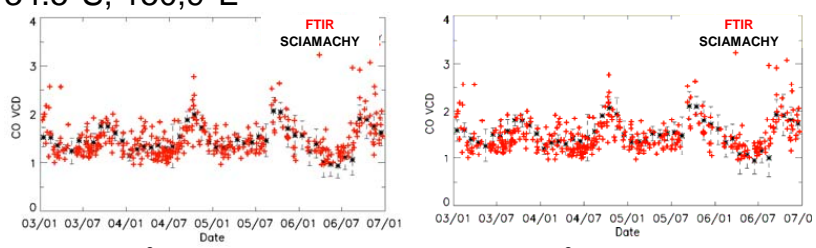

$\mathrm{s}=0.73, \quad \mathrm{r}^{2}=0.63, \quad \mathrm{~d}=-0.04$ $s=0.72, \quad r^{2}=0.59, \quad d=0.01$

Fig. 7. Continued.
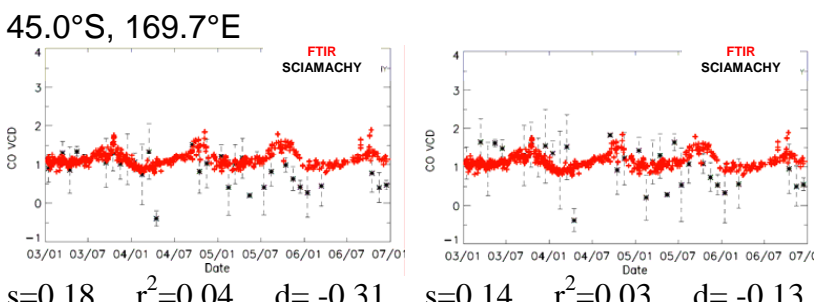

$\mathrm{s}=0.18, \quad \mathrm{r}^{2}=0.04, \quad \mathrm{~d}=-0.31 \quad \mathrm{~s}=0.14, \quad \mathrm{r}^{2}=0.03, \quad \mathrm{~d}=-0.13$

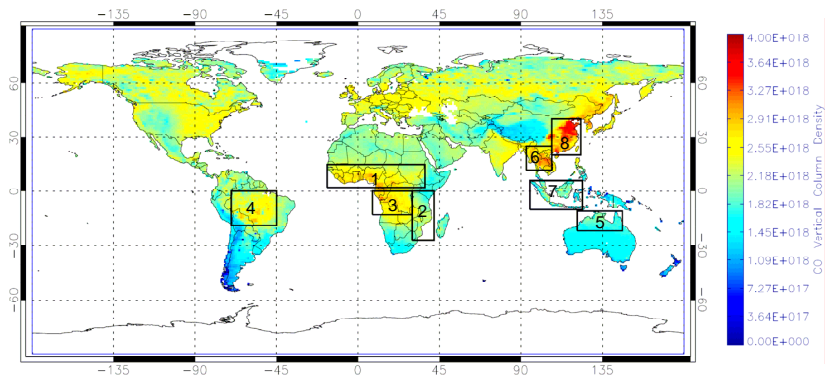

Fig. 8. Mean CO VCD retrieved from SCIAMACHY (2003 to 2005, units: $\operatorname{molec} \mathrm{cm}^{-2}$ ). The boxes indicate regions of high biomass burning or industrial activity that are selected for the comparison between satellite observations and model simulations (see Sect. 7). agreement with the FTIR measurements at most locations. Note that an initial validation of the uncorrected SCIAMACHY CO VCDs by FTIR observations was performed by Dils et al. (2006).

In Fig. 7 it can be also seen that the seasonal variation is already present in the uncorrected SCIAMACHY CO VCDs. However, due to the relatively small area $\left(8^{\circ} \times 8^{\circ}\right)$ around the FTIR stations (similar as in de Laat et al. 2010), the SCIAMACHY CO VCDs are also subject to large scatter (depending on the surface albedo and cloud cover). Figure A4 in the appendix presents time series averaged over larger areas, which show a much smoother seasonal variation. Here the uncorrected data reproduce very well the seasonal variations, although with substantial biases.

In Fig. 8 the global mean average CO VCD (2003 to 2006) from our SCIAMACHY retrieval is shown. It is obtained after applying the normalisation procedure using MO- 


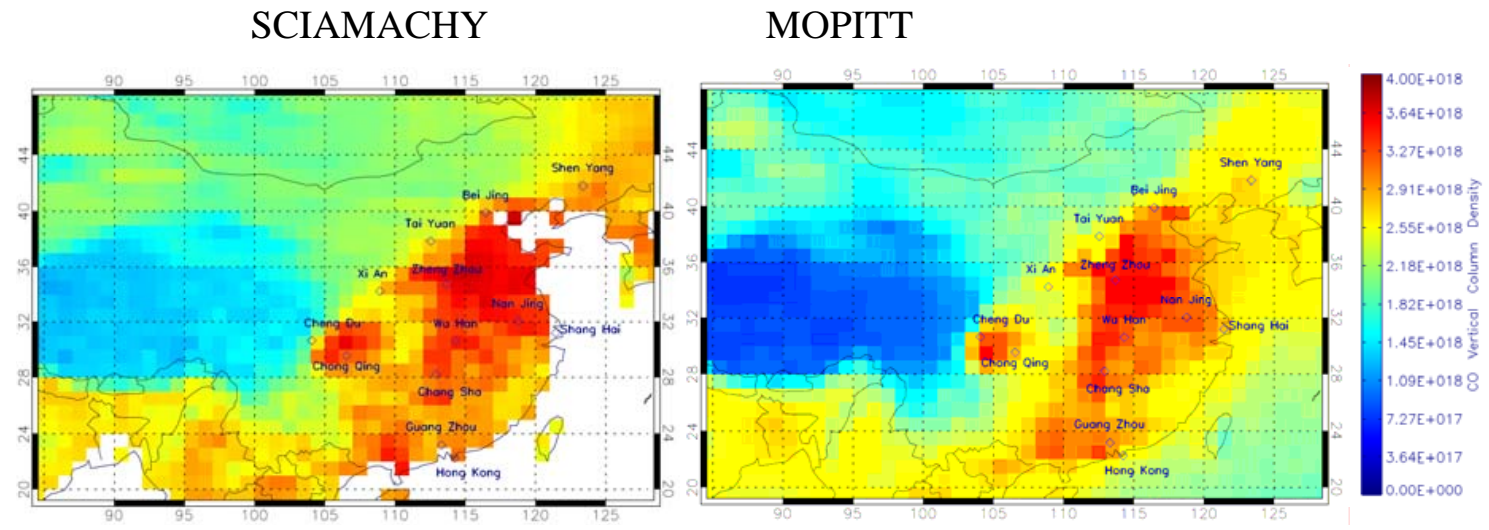

Fig. 9. Comparison of the spatial distribution of the CO VCD (average 2003 to 2005) over China derived from SCIAMACHY (left) and MOPITT version 4 (right).

no corrections

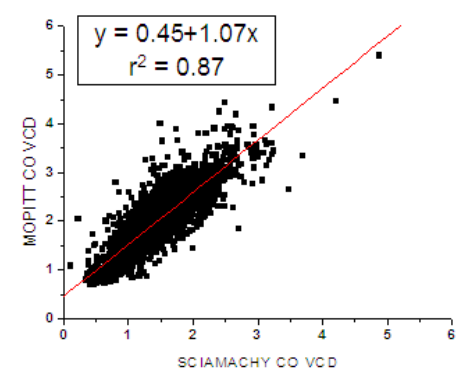

only MOPITT normalisation

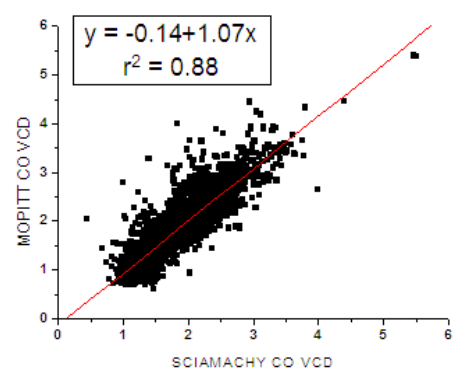

Also cloud correction

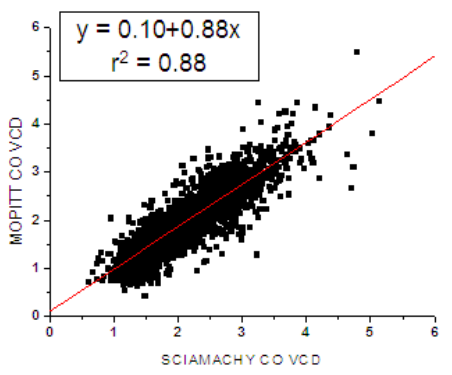

Fig. 10. Spatial correlation ( $1^{\circ}$ grid) for global average maps (2003-2005) of the CO VCD from MOPITT and SCIAMACHY (units: $10^{18} \mathrm{molec}^{-2}$ ). The different graphs are for different steps of the SCIAMACHY CO retrieval.

PITT observations over the ocean (see Sect. 3), skipping all observations with effective cloud fractions $>20 \%$, and applying the cloud correction as described above. Besides over regions with strong anthropogenic emission sources (like over China), enhanced CO VCDs are in particular found over regions with intense biomass burning.

In Fig. 9a zoom of Fig. 8 over East Asia is presented together with $\mathrm{CO}$ results from MOPITT. High values are found over highly populated regions as also reported by other studies (e.g., Buchwitz et al., 2007). In particular, the highest CO VCDs derived from SCIAMACHY coincide with the location of major Chinese cities.

\section{Comparison of SCIAMACHY with MOPITT over the continents}

In recent comparison studies between $\mathrm{CO}$ measurements from SCIAMACHY and MOPITT it was mostly found that the CO VCDs derived from SCIAMACHY are larger than those from MOPITT (e.g., Buchwitz et al., 2004, 2006a, 2007; Turquety et al., 2008), in agreement with the as- sumption that the $\mathrm{CO}$ concentrations close to the surface are higher than those assumed for the MOPITT a priori profiles (which represent current knowledge about the $\mathrm{CO}$ profiles, especially near the surface). However, these comparisons were often affected by the systematic biases of the SCIAMACHY CO VCDs, which complicated their quantitative interpretation.

In this section we compare CO VCDs from our retrieval algorithm with collocated MOPITT data. Due to the normalization procedure the SCIAMACHY CO VCDs can not be regarded as a completely independent data set. But the comparison of coincident CO VCDs from MOPITT and SCIAMACHY over the continents can yield important information on the consistency of the results of both satellite sensors over the continents. In particular the hypothesis can be tested whether the SCIAMACHY CO VCDs are systematic higher over areas with strong emission sources because of their higher sensitivity (compared to MOPITT) for the near-surface layers. Additional confidence on the quality of the SCIAMACHY CO data set can be gained from the investigation of the spatial and temporal patterns. 
Central Africa (region 1 in Fig. 8)
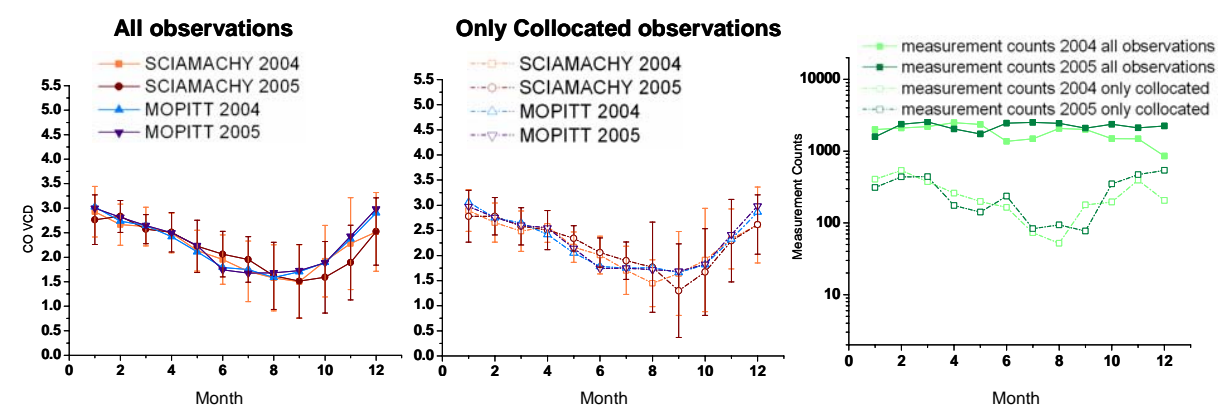

Central South America (region 4 in Fig. 8)
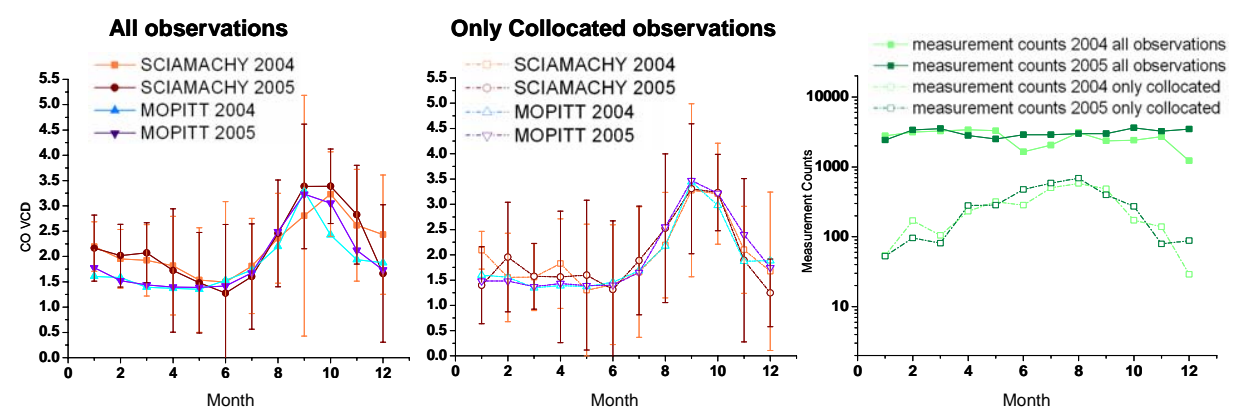

East China (region 8 in Fig. 8)
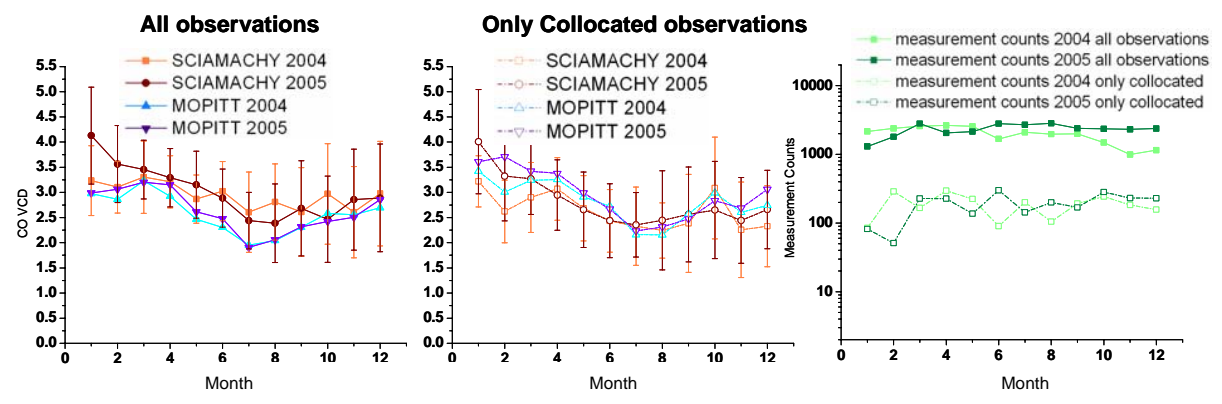

Fig. 11. Comparison of the monthly mean CO VCD (in units of $10^{18} \mathrm{molec}^{-2}$ ) derived from SCIAMACHY and MOPITT. In the left column of the figure all observations of SCIAMACHY and MOPITT within the selected regions (see Fig. 8) are considered. In the middle column only collocated and coincident observations of SCIAMACHY and MOPITT are used. Similar comparisons for other regions indicated in Fig. 8 are presented in the appendix. The error bar of SCIAMACHY refers to the unbiased estimator of a weighted population variance. The numbers of observations are indicated in the right column (please notice the logarithmic scale).

In a first step the spatial distribution (averages from 20032005 on a $1^{\circ}$ grid) of the CO VCD between MOPITT and SCIAMACHY are correlated. In Fig. 10 the correlation analyses for the different steps of the SCIAMACHY retrievals are shown. The normalisation using MOPITT data and the cloud correction have only little effect on the strength of the correlation indicating that already in the uncorrected SCIAMACHY CO VCDs the spatial patterns agree well with those of MOPITT. After applying the different correction steps, the bias between both data sets is reduced with the strongest impact from the normalisation using MOPITT data over the oceans.
In a second step (Fig. 11) we investigate the time series of monthly mean CO VCDs over three of the areas indicated in Fig. 8 (similar comparisons for other regions indicated in Fig. 8 are presented in Fig. A5 in the appendix; one example of the comparison for a region without strong $\mathrm{CO}$ emission sources was already presented in Fig. 1. In the left column of Fig. 11 the time series using all observations within the selected area are shown (for SCIAMACHY only observations with an effective cloud fraction $<20 \%$ are used). In the middle column of Fig. 11 only coincident observations between both sensors were used. Also shown are the respective numbers of observations (notice the logarithmic scale). 
Jan. to Mar. of 2003 to 2005

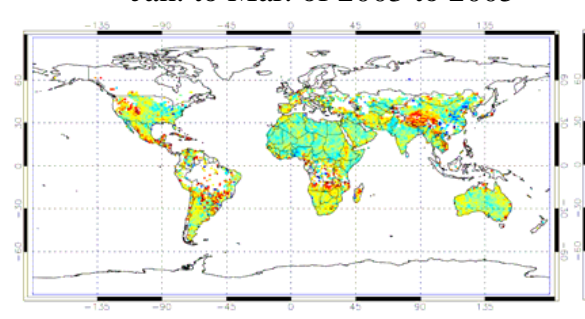

Jul. to Sep. of 2003 to 2005
Apr. to Jun. of 2003 to 2005

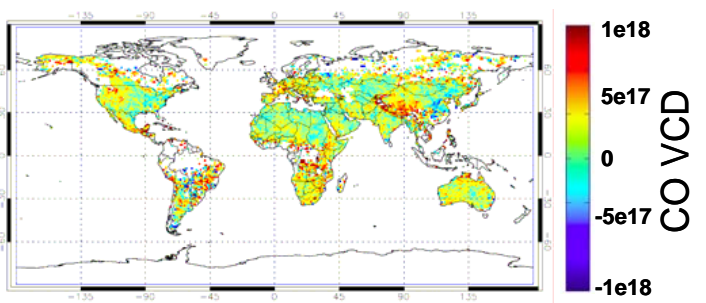

Oct. to Dec. of 2003 to2005

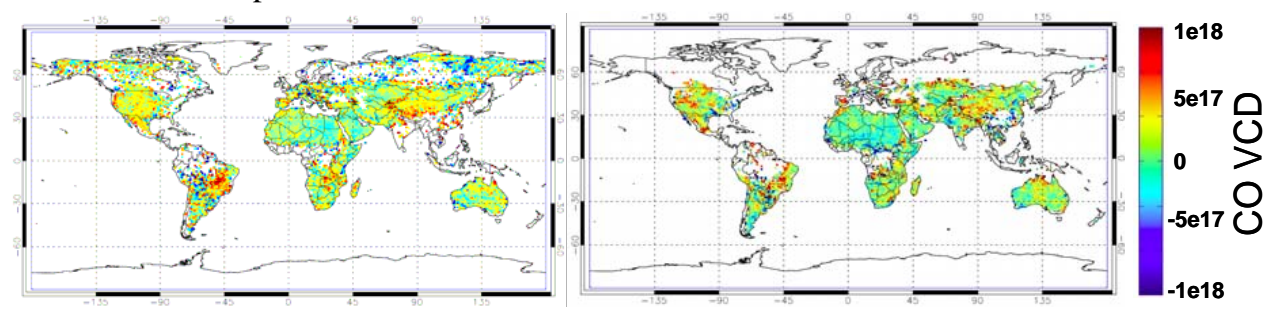

Fig. 12. Spatial distribution of averaged seasonal differences between SCIAMACHY and MOPITT CO columns with the same spatialtemporal sampling. White areas indicate missing values. It should be noted that over almost all regions the deviations are not significant according to the SCIAMACHY measurement uncertainties.

If only coincident observations are selected, the number of SCIAMACHY observations reduces strongly (by a factor 10 to 100$)$.

The interpretation of the results of the comparison is not straight-forward, since the true vertical $\mathrm{CO}$ concentration profiles are not known, and for the retrieval of both data sets different assumptions on the a priori profile were made. For MOPITT version $4 \mathrm{CO}$ VCDs the a priori even depends on location and season. Thus the comparison exercise can only be interpreted in a semi-quantitative way.

Over the biomass burning regions very similar seasonal cycles are found in both data sets. In most cases the SCIAMACHY CO VCDs are systematically higher than the MOPITT CO VCDs probably indicating the higher sensitivity of SCIAMACHY towards the surface. If only coincident observations of both sensors are considered (right parts of Fig. 11), over several regions (especially those shown in Fig. 11) the agreement between both sensors is much improved. However, in other regions (see Fig. A5 of the appendix), the CO VCDs from SCIAMACHY are still systematically higher than from MOPITT. This difference indicates that the near surface $\mathrm{CO}$ concentrations are probably underestimated by the MOPITT a priori profiles. Interestingly, in contrast to most biomass burning regions, the MOPITT a priori profiles seems to describe the atmospheric CO profiles over East China rather well.

Of course, at least part of the deviations might also be caused by other error sources. Especially for some regions (e.g., South Asia or Indonesia) and months the number of SCIAMACHY observations is relatively low and the cor- responding uncertainties of the SCIAMACHY observations are high. In other parts of the world, especially over South America, also the frequent occurrence of high clouds increases the uncertainty of the SCIAMACHY (and also MOPITT) observations (see also Fig. 6).

In a third exercise the spatial distributions of the CO VCD derived from both satellite instruments are compared for different seasons. In Fig. 12 the differences are shown using only coincident measurements. In general, good overall agreement is found with slightly higher SCIAMACHY CO VCDs over most parts of the world. Here it is important to note that over almost all regions the deviations are not significant according to the SCIAMACHY noise errors. Nevertheless, across large areas the deviations are consistent (e.g. over the US for July to September), and indicate systematic differences between MOPITT and SCIAMACHY. The largest differences between both sensors are found over South America and South-East Africa during the biomass burning seasons (see also Figs. 11 and A5).

Like SCIAMACHY observations, in principle also MOPITT observations should suffer from cloud effects, but for MOPITT only cloud free measurements were used. The clear/cloudy determination is based on both the MOPITT radiances themselves and a "cloud mask" produced from nearsimultaneous observations by the Terra/MODIS instrument. Even if some partly clouded observations were still included in the MOPITT data set, the effect of these clouds should be much smaller compared to SCIAMACHY, because even for completely cloud-free observations the sensitivity of MOPITT towards the near-surface layers is strongly reduced. 
As mentioned above, this direct comparison between the CO VCDs from SCIAMACHY and MOPITT can only be interpreted in a semi-quantitative way, because the true atmospheric $\mathrm{CO}$ concentration profiles are not known. A more quantitative comparison between both sensors is possible if profile information from atmospheric models is used (see also Turquety et al., 2008; Kopacz et al., 2010; de Laat et al., 2010); such a comparison is presented in Sect. 7.

\section{Overview of the atmospheric models}

Satellite observations from SCIAMACHY and MOPITT are compared to the results of three atmospheric models. MATCH and GEOS-Chem are offline chemistry transport models, driven by externally supplied meteorological files, while EMAC is a fully coupled, online chemistryclimate model (which in this case is nudged towards observed values).

\subsection{MATCH-MPIC}

MATCH-MPIC (Model of Atmospheric Transport and CHemistry - Max Planck Institute for Chemistry version) is a global, three dimensional chemical transport model representing tropospheric $\mathrm{O}_{3}, \mathrm{CH}_{4}, \mathrm{NO}_{\mathrm{x}}$, and VOC chemistry. MATCH-MPIC has been described and evaluated in detail (Rasch et al., 1997; Lawrence et al., 1999, 2003; von Kuhlmann et al., 2003). MATCH-MPIC is run in a semioffline mode, relying only on a limited set of input fields (surface pressure, geo potential, temperature, horizontal winds, surface latent and sensible heat fluxes, and zonal and meridional wind stresses). These fields are obtained from the NCEP GFS (National Centers for Environmental Prediction Global Forecast System, Kalnay et al., 1990). Fields are interpolated in time to the model time step of $30 \mathrm{~min}$, and used to diagnose online the transport by advection, vertical diffusion and deep convection, as well as the tropospheric hydrological cycle (water vapour transport, cloud condensate formation and precipitation). The model uses a combination of two convection parameterisations focusing on deep and shallow mixing (Zhang and McFarlane, 1995; Hack, 1994). Anthropogenic emissions are from the Emissions Database for Atmospheric Research (EDGAR) fast track 2000 emissions, which are based on the EDGAR 3.2 emissions inventory (Olivier and Berdowski, 2001). Biomass burning emission data are based on the Global Fire Emissions Database (GFED v2), van der Werf et al. (2006).

\subsection{EMAC}

The ECHAM/MESSy Atmospheric Chemistry (EMAC) model is a numerical chemistry and climate simulation system that includes sub-models describing tropospheric and middle atmosphere processes and their interaction with oceans, land and human influences (Jöckel et al., 2006). It uses the Modular Earth Sub-model System (MESSy; Jöckel et al., 2005) to link multi-institutional computer codes. The core atmospheric model is the 5th generation European Centre Hamburg general circulation model (ECHAM5, Roeckner et al., 2006). For the present study we applied EMAC in the T42L90MA-resolution, i.e. with a spherical truncation of T42 (corresponding to a quadratic Gaussian grid of approx. 2.8 by 2.8 degrees in latitude and longitude) with 90 vertical hybrid pressure levels up to $0.01 \mathrm{hPa}$ (middle atmosphere) and at T106L31-resolution (corresponding to 1.1 by 1.1 degrees in latitude and longitude) and 31 vertical levels up to $10 \mathrm{hPa}$. The T106L31 set-up has a higher horizontal and approximately the same vertical resolution in the troposphere as T42L90MA, and we refer to the former as EMAC-H and the latter as EMAC-L. In the EMAC-L set-up, the biomass burning emissions from the Global Fire Emission Database (GFED v2.1) have been used, and the anthropogenic emissions from the EDGAR3.2FT2000 database. For the EMAC-H set-up we applied updated anthropogenic emissions, based on the EDGARV4.0 (see http://edgar.jrc.ec. europa.eu/index.php) with a resolution of $0.1 \times 0.1$ degree for the year 2005 and the biomass burning inventory GFED v3.1 (see http://www.falw.vu/ $\sim$ gwerf/GFED/), with a resolution of $0.5 \times 0.5$ degree.

Model output for analysis was triggered every $5 \mathrm{~h}$ simulation time. For EMAC-L, the prognostic variables vorticity, divergence, temperature and the (logarithm of the) surface pressure have been nudged to the operational ECMWF analysis data in order to allow a point-to-point comparison to the satellite data (see Jöckel et al. (2006) for further details), whereas for EMAC-H no nudging was applied. Stratospheric and tropospheric gas-phase and heterogeneous chemistry in both set-ups was calculated with the sub-model MECCA (Module Efficiently Calculating the Chemistry of the Atmosphere, Sander et al., 2005), aqueous-phase chemistry in cloud droplets and wet scavenging with the submodel SCAV (Tost et al., 2006). Primary emissions and dry deposition of trace gases and aerosols were calculated with the sub-models ONLEM, OFFLEM, TNUDGE (Kerkweg et al., 2006a and DRYDEP (Kerkweg et al, 2006b), respectively. More details on the overall model set-up (including emissions) are presented by Jöckel et al. (2006 and 2010) and Pozzer et al. (2007). The 5-hourly 3-D CO output was converted to daily mean $\mathrm{CO}$ values and interpolated to the retrieval levels of MOPITT. In addition, the total CO column was calculated from the model output on the basis of the daily meteorological conditions as simulated by the model. For the EMAC simulations the convection scheme of Tiedtke (1989) and Nordeng (1994) was applied. 


\subsection{GEOS-Chem}

GEOS-Chem (Bey et al., 2001) is a global 3-D chemical transport model for atmospheric composition. The model is driven by assimilated meteorological data from the Goddard Earth Observing System (GEOS) of the NASA Global Modeling and Assimilation Office (GMAO). The model simulates detailed tropospheric $\mathrm{O}_{3}-\mathrm{NO}_{\mathrm{x}}$-hydrocarbon chemistry, including the radiative and heterogeneous effects of aerosols.

In this study, version v8-01-01 of GEOS-Chem (http: //acmg.seas.harvard.edu/geos/) is used, with meteorological fields in GEOS version 4 (GEOS-4) at 6-h time steps (3h for surface variables and the mixing depth). The horizontal resolution is $4^{\circ}$ latitude by $5^{\circ}$ longitude. Vertically, there are 30 levels of which $\sim 15$ in the troposphere from 1000 to $100 \mathrm{hPa}$. The anthropogenic emission inventory is based on the Emission Database for Global Atmospheric Research (EDGAR) (Oliver and Berdowshi, 2001). Emissions from biofuel combustion are from Yevich and Logan (2003). Biogenic emissions are from the Model of Emissions of Gases and Aerosols from Nature (MEGAN) (Guenther et al., 2006). For moist convection, the model treats deep and shallow convection separately following the schemes of Zhang and McFarlane (1995) and Hack (1994). Biomass burning emission data are based on the Global Fire Emissions Database (GFED v2), van der Werf et al. (2006).

\section{Comparison between measurements and models}

In this section, we compare the satellite observations of both sensors with results from the three global atmospheric chemistry models (MATCH, EMAC low and high resolution, $\mathrm{L}$ and $\mathrm{H}$, and GEOS-Chem), as introduced in Sect. 6. In addition, the $\mathrm{CO}$ emissions used in the models and fire counts as a qualitative indicator for $\mathrm{CO}$ emissions from biomass burning are included in this comparison. As for the comparison between SCIAMACHY and MOPITT observations (Sect. 5), first the time series over selected regions are shown (Sect. 7.1). These comparisons allow in particular to study possible differences in the seasonal cycle. In addition, also global maps of the differences for different seasons are presented (Sect. 7.2).

Before these comparisons are presented and discussed, some general aspects of this comparison should be considered. In contrast to the comparison between MOPITT and SCIAMACHY (Sect. 5), for the comparison between measurements and model results information on the vertical $\mathrm{CO}$ concentration profile is available (from the model simulations), which is used to correct for the height dependent sensitivities of both sensors. Of course, the simulated CO profiles do not necessarily represent the true atmospheric profiles. Nevertheless, in general they should describe the atmospheric CO profiles more realistically than the a priori assumptions used in the satellite retrievals (at least for SCIA-
MACHY, for which only a fixed a priori profile was used). Thus from the comparison between observations and model results, more precise conclusions about the agreement between both sensors than from their direct comparison might be drawn (e.g., Turquety et al., 2008), especially in cases for which good agreement between model simulations and observations is generally found. For the comparison between measurements and model results, the following conclusions can be drawn.

If it is assumed that the model simulations represent the true atmospheric profiles (and the measurements would have no errors), exact agreement between measurements and model simulations must be expected (but only for the part of the atmospheric profile for which the sensitivity of the satellite observation is $>$ zero). However, agreement between measurements and model results might also be found as a result of compensating errors of measurements and models. Thus agreement between observations and measurements might only be seen as an indication (not as evidence) that both measurements and model simulations are correct.

On the other hand, disagreement is an unambiguous indication for errors of either the measurements or model simulations (or both).

It should also be noted that - for practical reasons - the altitude dependent sensitivity is considered in different ways for both satellite instruments. For the comparison of the model results and SCIAMACHY observations, the (relative) model profiles (instead of the standard profile, see Fig. 4) are used to correct for the height dependent measurement sensitivity. According to Eqs. (6) and (7) we get:

$\mathrm{VCD}_{\text {SCIA, model }}=\frac{\mathrm{VCD}_{\text {SCIA }} \cdot \mathrm{AMF}_{\text {geo }}}{\mathrm{AMF}_{\text {total, model }}}$

with

$\mathrm{AMF}_{\text {total }, \text { model }}=\frac{\sum_{i} \mathrm{AMF}_{\mathrm{box}}\left(z_{i}\right) \cdot c_{\mathrm{CO}, \text { model }}\left(z_{i}\right)}{\sum_{i} c_{\mathrm{CO}, \text { model }}\left(z_{i}\right)}$

and $\mathrm{c}_{\mathrm{CO} \text {,model }}\left(z_{i}\right)$ the $\mathrm{CO}$ concentration of the model simulation at layer $i$.

The resulting VCD SCIA,model is the CO VCD which would be "seen" from SCIAMACHY if the model was the truth. It is then compared to the CO VCD obtained from the vertical integration of the $\mathrm{CO}$ profile from the model simulation.

For the comparison between the model results and MOPITT observations, the CO VCD from the MOPITT v4 data product is taken and compared to the $\mathrm{CO}$ profiles from the model simulations after applying the MOPITT averaging kernel and a priori.

$\mathrm{VCD}_{\text {model, }, \text { MOPITT }}=\sum_{i}\left[x_{a}\left(z_{i}\right)+A\left(z_{i}\right)\left(x_{\text {model, profile }}\left(z_{i}\right)-x_{a}\left(z_{i}\right)\right)\right]$

Here $\mathrm{VCD}_{\text {model,MOPITT }}$ is the model CO VCD after applying the MOPITT column averaging kernel $\mathrm{A}\left(z_{i}\right)$ and a priori profile $x_{a}\left(z_{i}\right)$ (expressed as partial column densities) where $i$ indicates the MOPITT vertical layer. 
Central Africa (region 1 in Fig. 8)

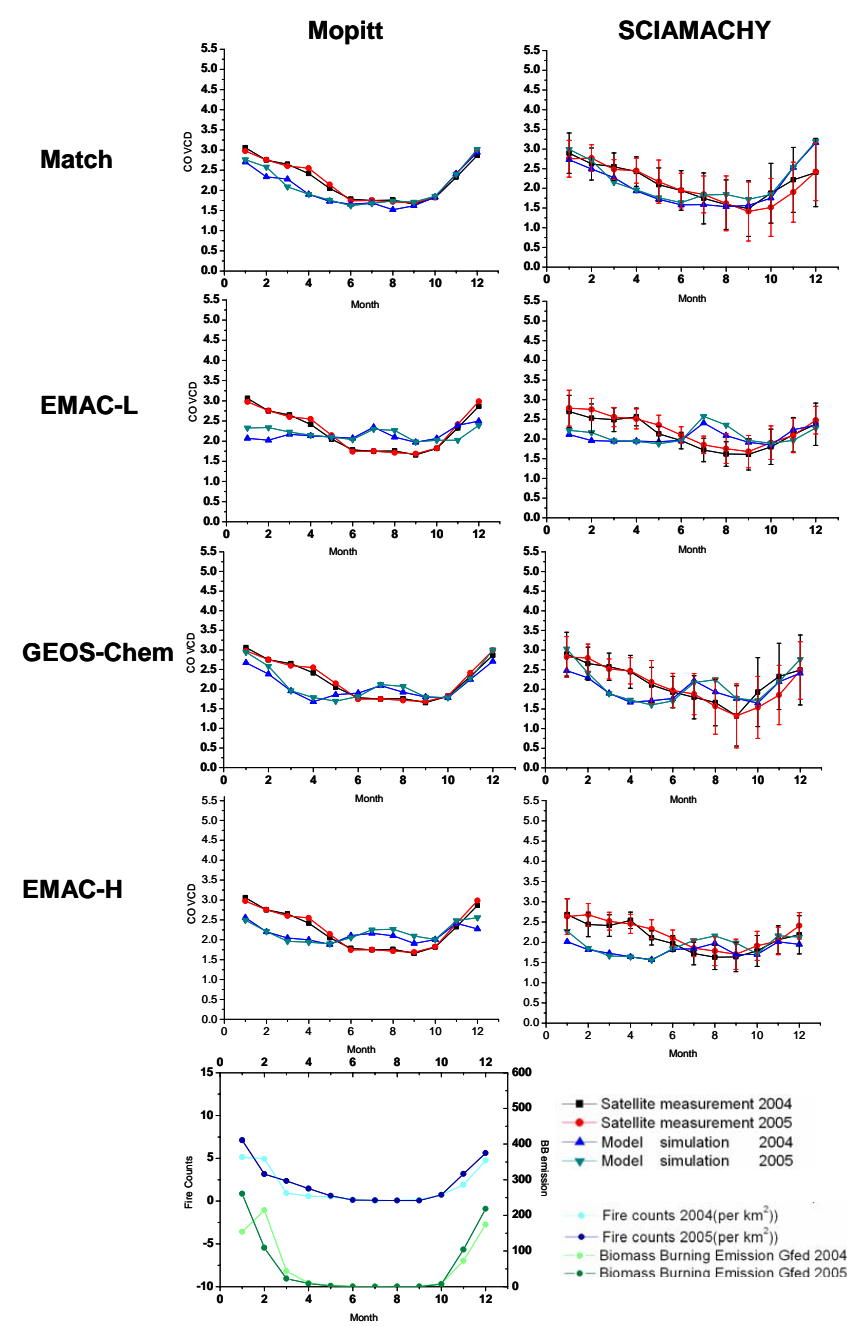

Central South America (region 4 in Fig. 8)

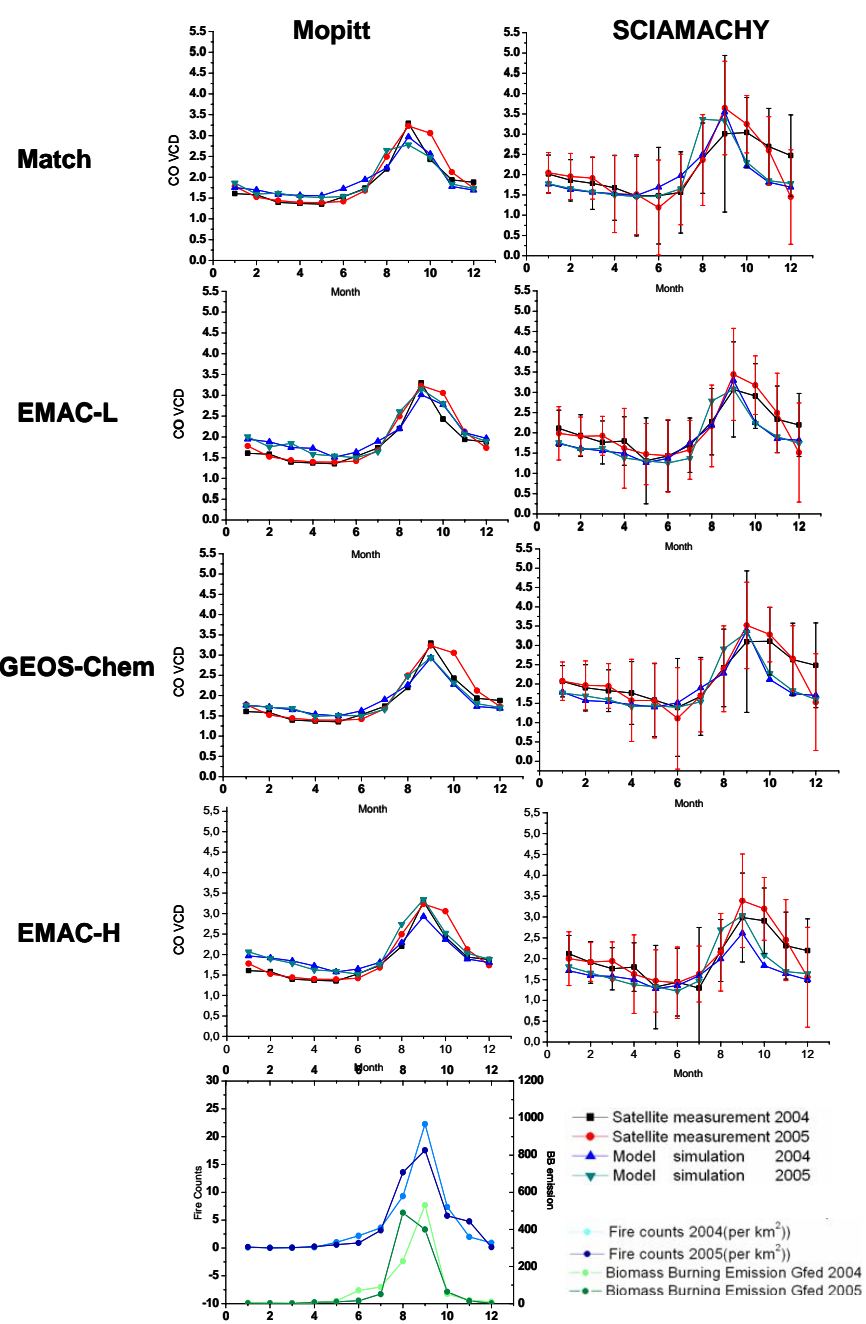

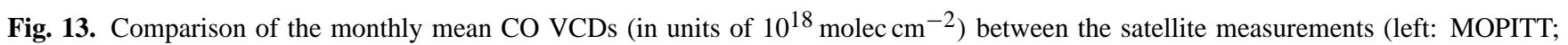
right: SCIAMACHY) and model simulations for three of the regions indicated in Fig. 8 (similar comparisons for the other regions indicated in Fig. 8 are shown in Fig. A6 in the appendix). All comparisons are done for only collocated measurements/model results; also the specific sensitivities of the satellite instrument have been considered (see text). In the bottom row fire counts from ATSR (in units of $10^{-4}$ per km ${ }^{2}$ per month), and GFED emissions used in the models (in units of $10^{13}$ molecules $\mathrm{cm}^{-2} \mathrm{~s}^{-1}$ ) are shown. The error bar of SCIAMACHY refers to the unbiased estimator of a weighted population variance. EMAC-L refers to low (T42) and EMAC-H to high (T106) spatial resolution.

Despite the different formalities of the comparison, the interpretation of the respective differences is identical: cases for which the satellite measurements are higher (lower) than the model results indicate an underestimation (overestimation) of the true $\mathrm{CO}$ profile by the model, e.g., caused by an underestimation (overestimation) of the emission sources (similar conclusions can of course be also drawn for the measurement errors). However, one important difference in the interpretation of the comparisons for the different sensors exists: the results of the comparison allow only conclusions for the altitude range for which the satellite instruments are sensitive. In particular, only the comparison between SCIAMACHY observations and model simulations can yield information about the $\mathrm{CO}$ distribution in the lowest atmospheric layers.

\subsection{Comparison of time series}

In Fig. 13 the time series of monthly averaged CO VCDs retrieved from both satellite sensors together with the corresponding $\mathrm{CO}$ VCDs from the model simulations are presented for three of the regions indicated in Fig. 8 (central Africa, central South America, and East China). The respective time series for the other regions indicated in Fig. 8 are presented in the appendix. Note that only coincident pairs of measurements and model results are considered (but the coincidences differ for the different combinations of satellite 


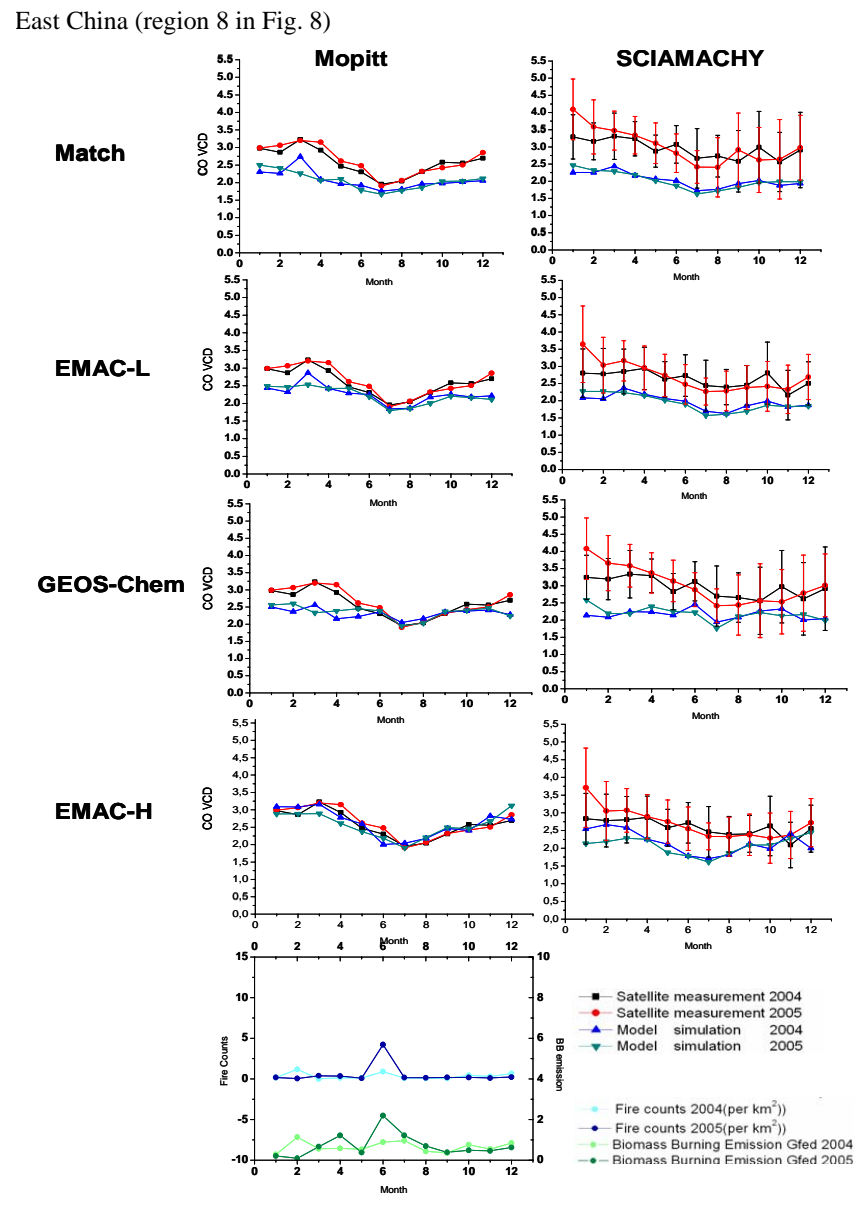

Fig. 13. Continued.

sensors and models). The height-dependent sensitivities of SCIAMACHY and MOPITT are considered as described above.

The different rows of the panels of Fig. 13 present the comparisons with the different models (left column: MOPITT, right column: SCIAMACHY). In the bottom row the seasonal variation of the GFED emissions and the fire counts is shown.

In most biomass burning regions a clear seasonal variation of the intensity of biomass burning exists (as indicated by the fire counts), which is in general well reproduced between the measurements and model results. However, there is also one interesting exception: for "Central Africa" (region 1 in Fig. 8) the models (except for MATCH) show a second maximum of the CO VCD in summer, when no fires are detected. Also, this second maximum is not seen in the satellite observations. This discrepancy might indicate artefacts introduced by errors in the description of the atmospheric transport (e.g., transport of $\mathrm{CO}$ emitted from biomass burning south of the considered area, where enhanced CO VCDs are found in summer, see Fig. A6 in the appendix). Especially the location of the ITCZ and its representation in the model may play a crucial role in particular when considering the separation between region (1), (2) and (3) in Fig. 8. Respective errors might be introduced in the models due to the limited horizontal resolution, although the problem is found in EMAC-L and $-\mathrm{H}$, but found somewhat reduced at higher resolution. Also for Southern Asia (region 6) and Indonesia (region 7), transport of pollutants probably plays an important role, but in this case transport is well described by the models for both regions. Although almost no fires occur in these regions after July, secondary maxima are found in the observations and model results in autumn.

Another interesting finding is that in most cases the MOPITT results agree much better with the model results than the SCIAMACHY results, while SCIAMACHY CO VCDs are generally higher than the model CO VCDs (especially in South America, Southeast and Southwest Africa, North Australia and Southern Asia). Also over East China higher CO VCDs are observed by SCIAMACHY. This indicates that current emission estimates used by the models for these regions are probably too low, and it was so far difficult (if not impossible) to identify this underestimation using only MOPITT observations (because of the low sensitivity for the near-surface layers).

\subsection{Comparison of global maps}

In order to gain insight in the spatial patterns of the differences between model and measurement results, we also calculated global maps of these differences for four seasons. These maps between the satellite observations (SCIAMACHY or MOPITT) and model simulations (MATCH, EMAC-L and -H, GEOS-Chem) are shown in Fig. 14. For SCIAMACHY only observations over land were considered, because the normalisation procedure of SCIAMACHY data (see Sect. 3) was performed over the oceans. Note that again only coincident pairs of measurements and model results were considered; however, different coincidences were used for the different satellite instruments. The height dependence of the measurement sensitivity was taken into account as described above.

In general the findings of this comparison are similar to those of the comparison of the time series in Fig. 13. Over regions with strong $\mathrm{CO}$ sources the models mainly underestimate the observed CO VCD. As already seen in Fig.13, this underestimation is systematically larger for the comparison with SCIAMACHY. However, there are also some regions where the models systematically overestimate the observed CO VCDs; this effect is most pronounced in autumn over Africa (around the equator) and in summer in the western Amazon region, and in general during winter and spring in the EMAC and MATCH simulations in the southern hemisphere. Interestingly, similar to the general underestimation by the models, the magnitude of the difference is larger for SCIAMACHY observations compared to those of the MOPITT observations. This indicates that also in the 
a: SCIAMACHY - EMAC-L

Jan. to Mar. of 2004 to 2005

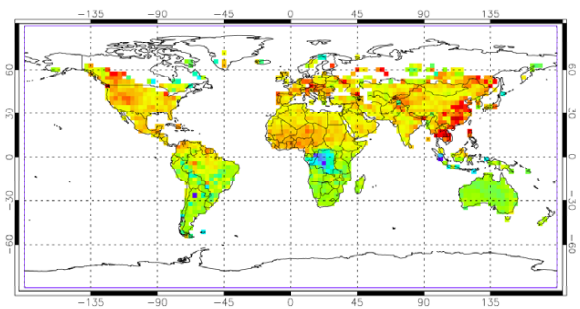

Jul. to Sep. of 2004 to 2005

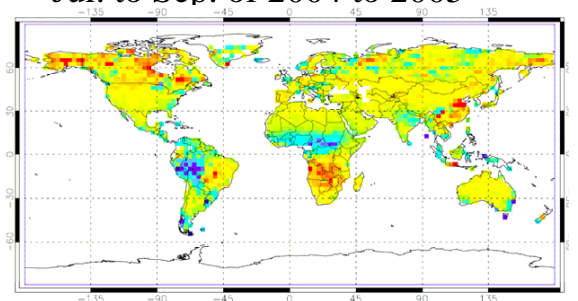

b: MOPITT - EMAC-L

Jan. to Mar. of 2004 to 2005

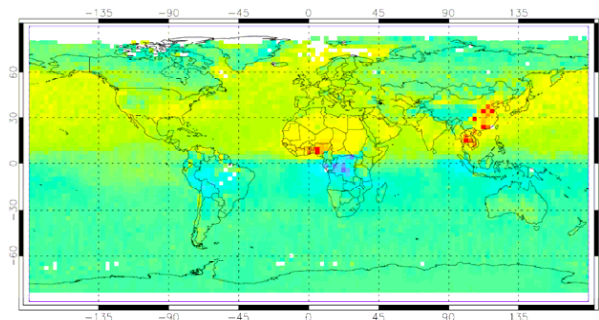

Jul. to Sep. of 2004 to 2005

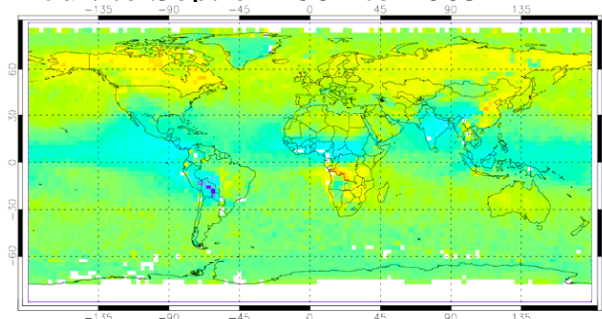

Apr. to Jun. of 2004 to 2005
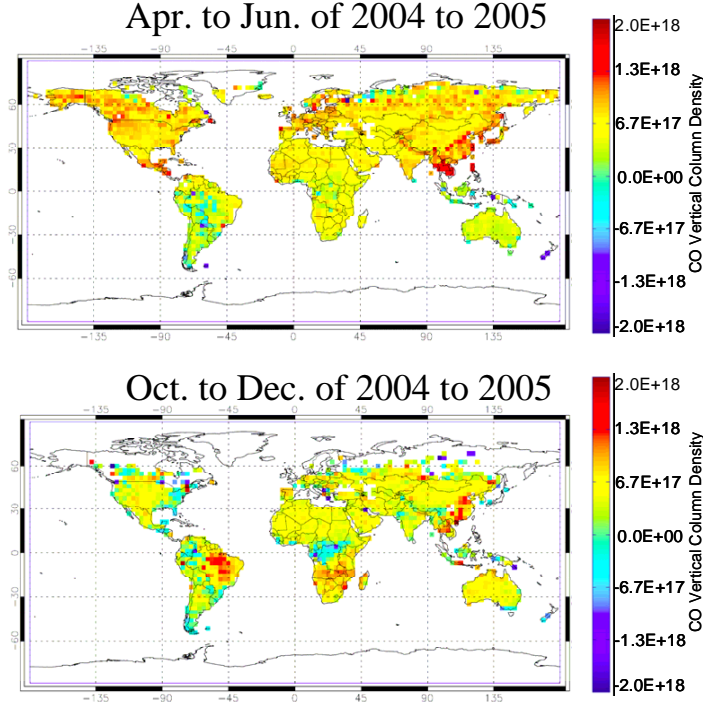

Apr. to Jun. of 2004 to 2005

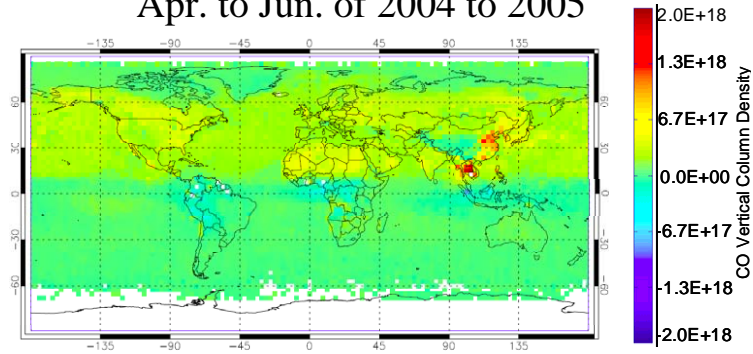

Oct. to Dec. of 2004 to 2005

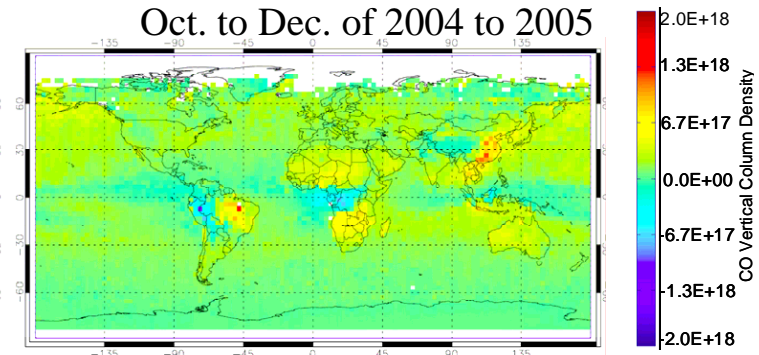

Fig. 14. Spatial distribution of averaged seasonal differences between satellite measurements (SCIAMACHY and MOPITT) and model (MATCH, EMAC, and GEOS-Chem) results of the CO VCD. EMAC-L refers to low (T42) and EMAC-H to high (T106) spatial resolution. Only coincident measurements were considered, and the height dependence of the measurement sensitivities was taken into account. White areas indicate missing values.

cases where models show higher CO VCDs than the measurements, the differences in the $\mathrm{CO}$ concentrations probably occur in the lowest layers of the atmosphere. It might be interesting to note that over desert regions, MOPITT CO VCDs are often higher than the model results indicating a possible "desert bias" as discussed in de Laat et al. (2010) and George et al. (2009).

\section{Conclusions}

We developed a new data set of CO VCDs from SCIAMACHY observations. To account for biases of the SCIAMACHY CO retrievals (varying with time and latitude) we apply a normalisation procedure using coincident MOPITT observations over the oceans. This normalisation procedure is applied on a daily basis for different latitude ranges; thus artificial offsets in the SCIAMACHY CO data are corrected 


\section{c: SCIAMACHY - MATCH}

Jan. to Mar. of 2004 to 2005

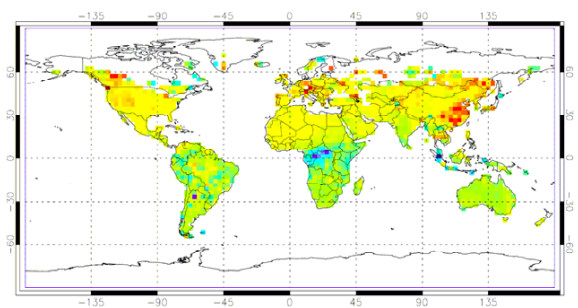

Jul. to Sep. of 2004 to 2005

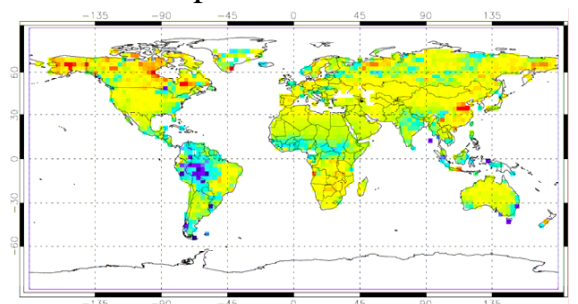

d: MOPITT - MATCH

Jan. to Mar. of 2004 to 2005

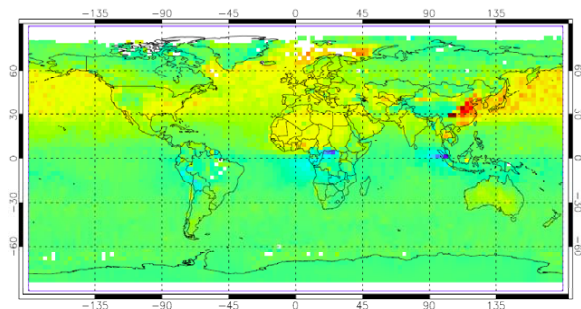

Jul. to Sep. of 2004 to 2005

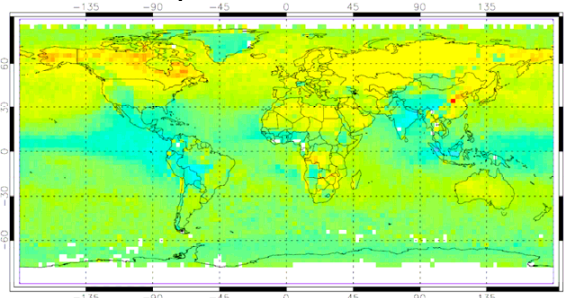

Apr. to Jun. of 2004 to 2005
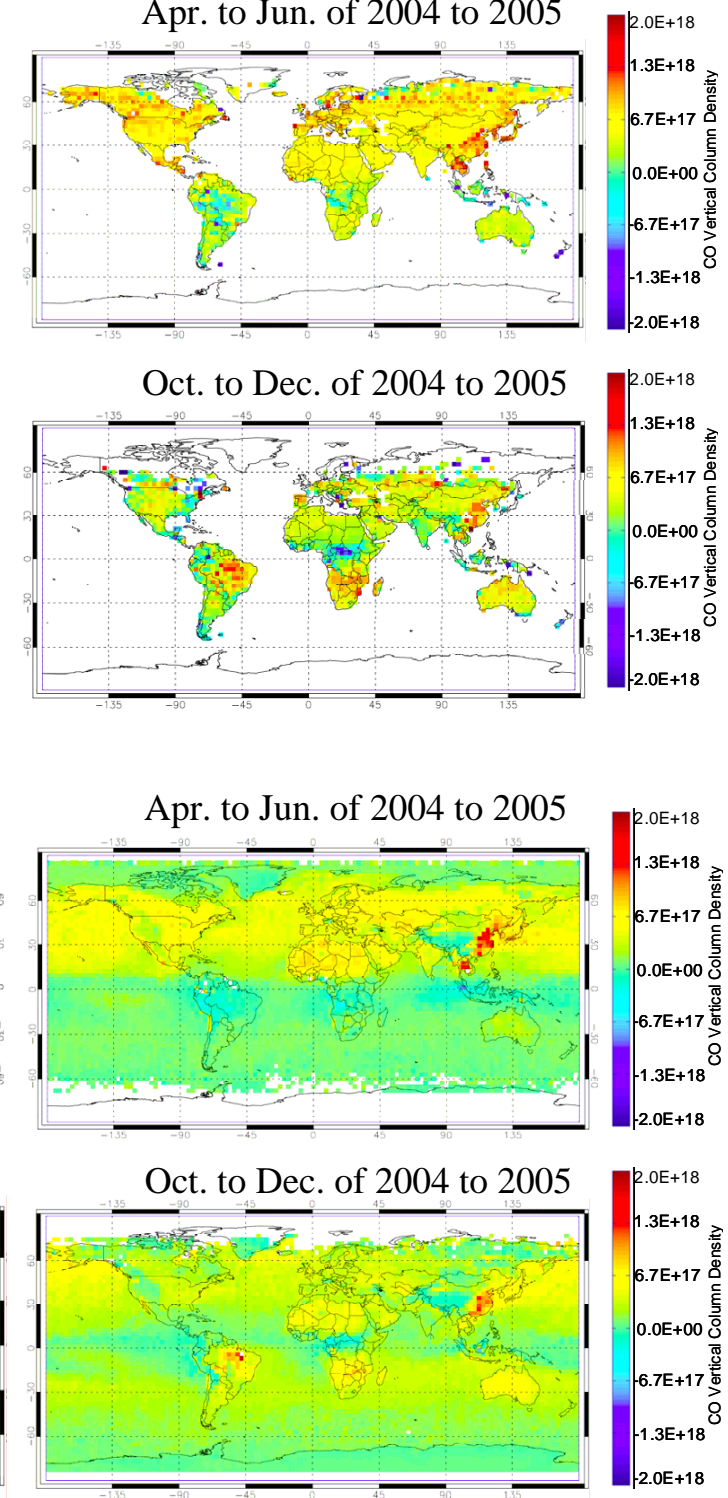

Fig. 14. Continued.

depending on season and latitude. While the new SCIAMACHY CO data set can not be considered as fully independent from MOPITT data, it can be used for the investigation of the $\mathrm{CO}$ distribution over the continents, where all important $\mathrm{CO}$ emission sources are located. We used only SCIAMACHY observations with an effective cloud fraction $<20 \%$ and applied a correction for the remaining cloud effects depending on effective cloud fraction, cloud top height and surface albedo. To our knowledge, no explicit cloud correction has so far been applied to SCIAMACHY CO observations. An implicit cloud correction based on simultaneously retrieved $\mathrm{CH}_{4}$ absorptions was, however, applied by
Buchwitz et al. (2007). According to our study, omission of a cloud correction can lead to systematic errors up to $>100 \%$, especially over polluted regions. Unfortunately, no ground based FTIR stations at largely polluted sites are available for validation. Thus, such large cloud effects could not be demonstrated by comparison with FTIR observations. Nevertheless, comparison of our SCIAMACHY CO data set with several ground based stations shows in most cases a better agreement after application of the cloud correction.

We compared the new data set of SCIAMACHY CO VCDs with coincident MOPITT observations over land and found in general good consistency. One interesting finding of 


\section{e: SCIAMACHY - EMAC-H}

Jan. to Mar. of 2004 to 2005

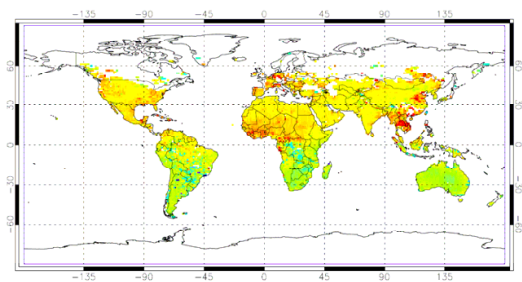

Jul. to Sep. of 2004 to 2005

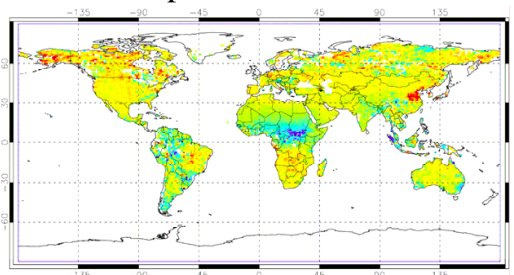

f: MOPITT - EMAC-H

Jan. to Mar. of 2004 to 2005

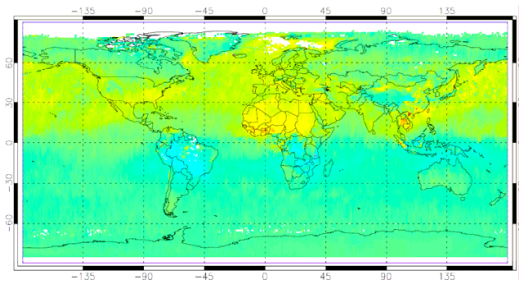

Jul. to Sep. of 2004 to 2005

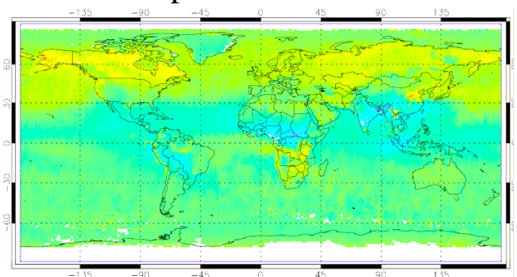

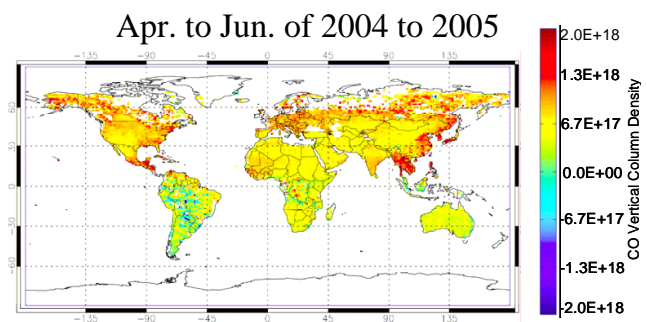
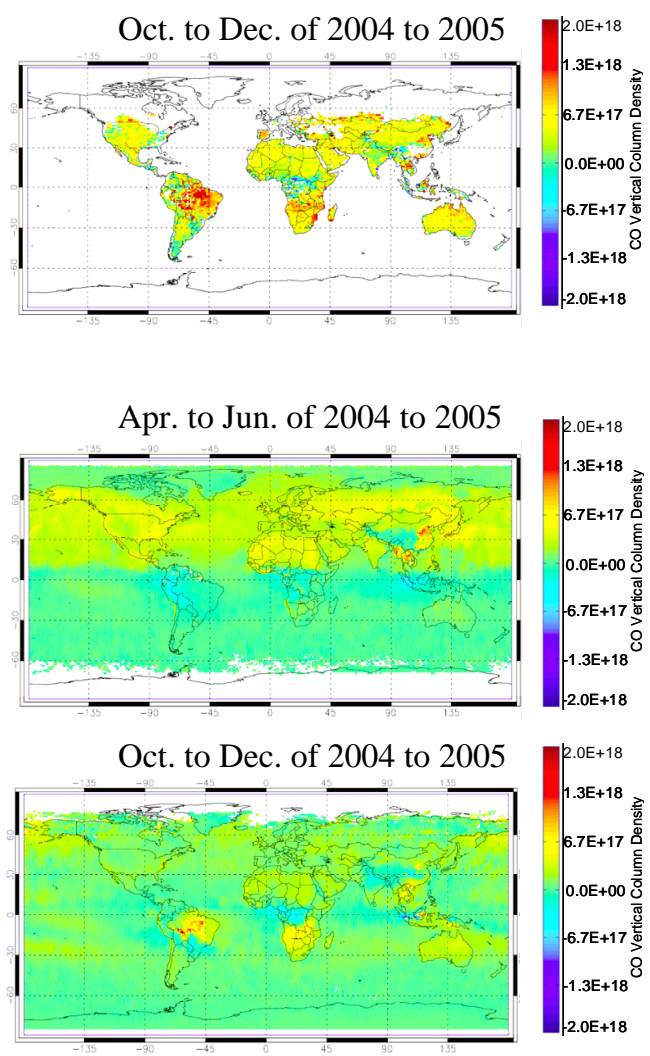

Fig. 14. Continued.

this comparison is that the agreement between both instruments strongly improves if only coincident measurements are considered. However, usually the SCIAMACHY observations showed still slightly higher values compared to MOPITT, in agreement with several other studies (e.g., Buchwitz et al., 2004, 2006a, 2007; Turquety et al., 2008).

Compared to MOPITT observations, SCIAMACHY observations are more sensitive to the atmospheric layers directly above the surface. In these layers not only most $\mathrm{CO}$ emissions occur; this part of the atmosphere is also critical for health and safety.

We compared observations both from MOPITT and SCIAMACHY to the results of different atmospheric models (MATCH, EMAC-L and -H, GEOS-Chem). For the comparison only coincident measurements/model results were selected, and we considered explicitly the height depen- dent sensitivity of both satellite instruments. The comparison shows that over many regions with strong emission sources (like biomass burning or anthropogenic emissions) the simulated CO VCDs are systematically smaller than those of the satellite observations. In particular, for most cases, the difference between SCIAMACHY and the models is larger than those between MOPITT and the models. Because of the reduced sensitivity of MOPITT towards the lowest part of the atmosphere, we thus conclude that especially the atmospheric $\mathrm{CO}$ concentrations close to the surface are probably underestimated by the models. It also appears that discrepancies between models and observations are largely due to emission strengths rather than model resolution. Our findings probably indicate that the $\mathrm{CO}$ emission inventories used for the model simulations may largely underestimate the true sources. We have no direct indications whether this 


\section{g: SCIAMACHY - GEOS-Chem}

Jan. to Mar. of 2004 to 2005
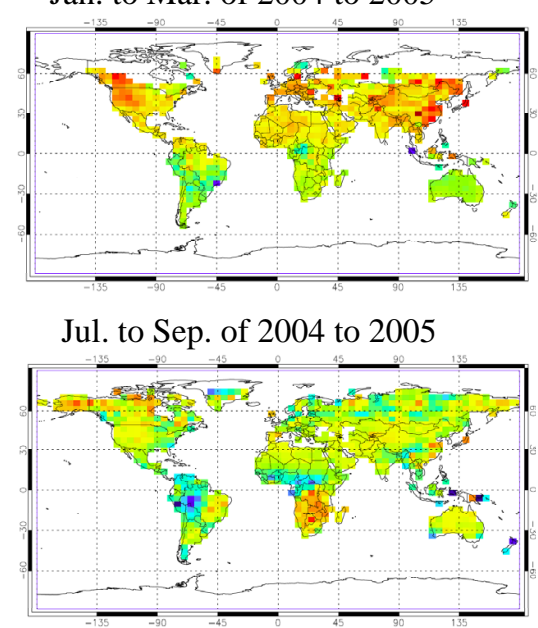

h: MOPITT - GEOS-Chem

Jan. to Mar. of 2004 to 2005

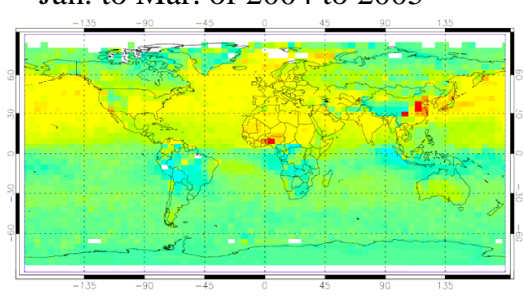

Jul. to Sep. of 2004 to 2005

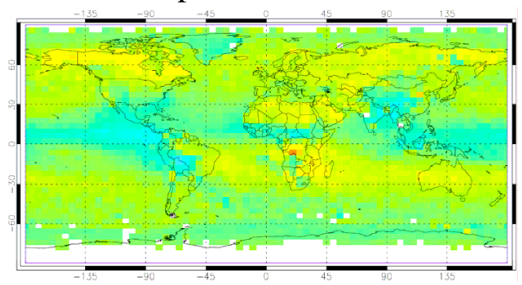

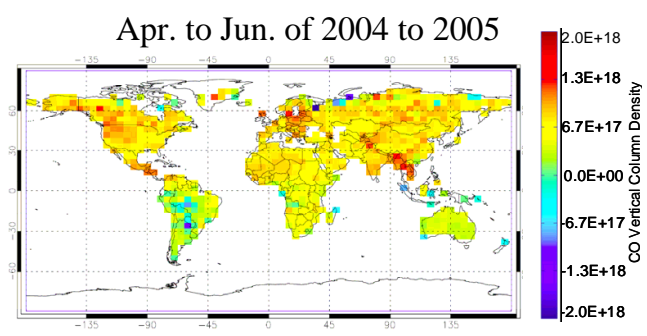
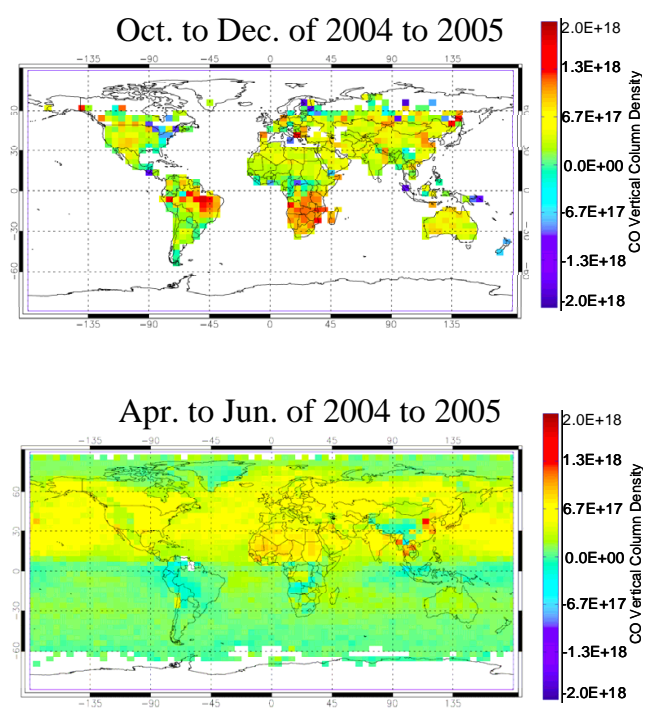

Oct. to Dec. of 2004 to 2005

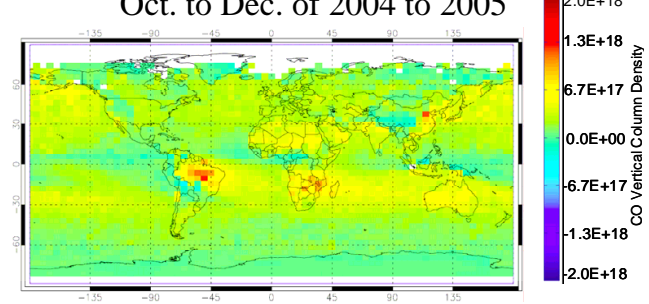

Fig. 14. Continued.

underestimation is caused by uncertainties in the amount of burned biomass or the $\mathrm{CO}$ emission factors (see Andreae and Merlet, 2001; van der Werf et al., 2006; Akagi et al., 2011), but other studies (e.g. Liu et al., 2005) indicate that uncertainties in emission factors probably play the dominant role.

Besides most biomass burning regions, especially over East China the actual CO emissions seem to be much larger than found in the emission inventories. Similar findings were also derived in several other studies, especially with respect to the GFED biomass burning emissions (e.g., Liu et al., 2005; Gloudemans et al., 2006, 2009; de Laat et al., 2006, 2007, 2010; Kopacz et al., 2010). It should of course be noted that we can not completely rule out the possibility that our SCIAMACHY CO retrieval overestimates the true CO VCDs. Interestingly, for some biomass burning regions (e.g., in the western Amazon region in summer and around the equator in Africa in autumn) the model simulations seem to overestimate the atmospheric $\mathrm{CO}$ concentrations. We suggest that our SCIAMACHY CO data set can be used to improve the current $\mathrm{CO}$ emission inventories on a global scale, primarily by assuming higher emission factors of $\mathrm{CO}$ from biomass burning. 
Appendix A
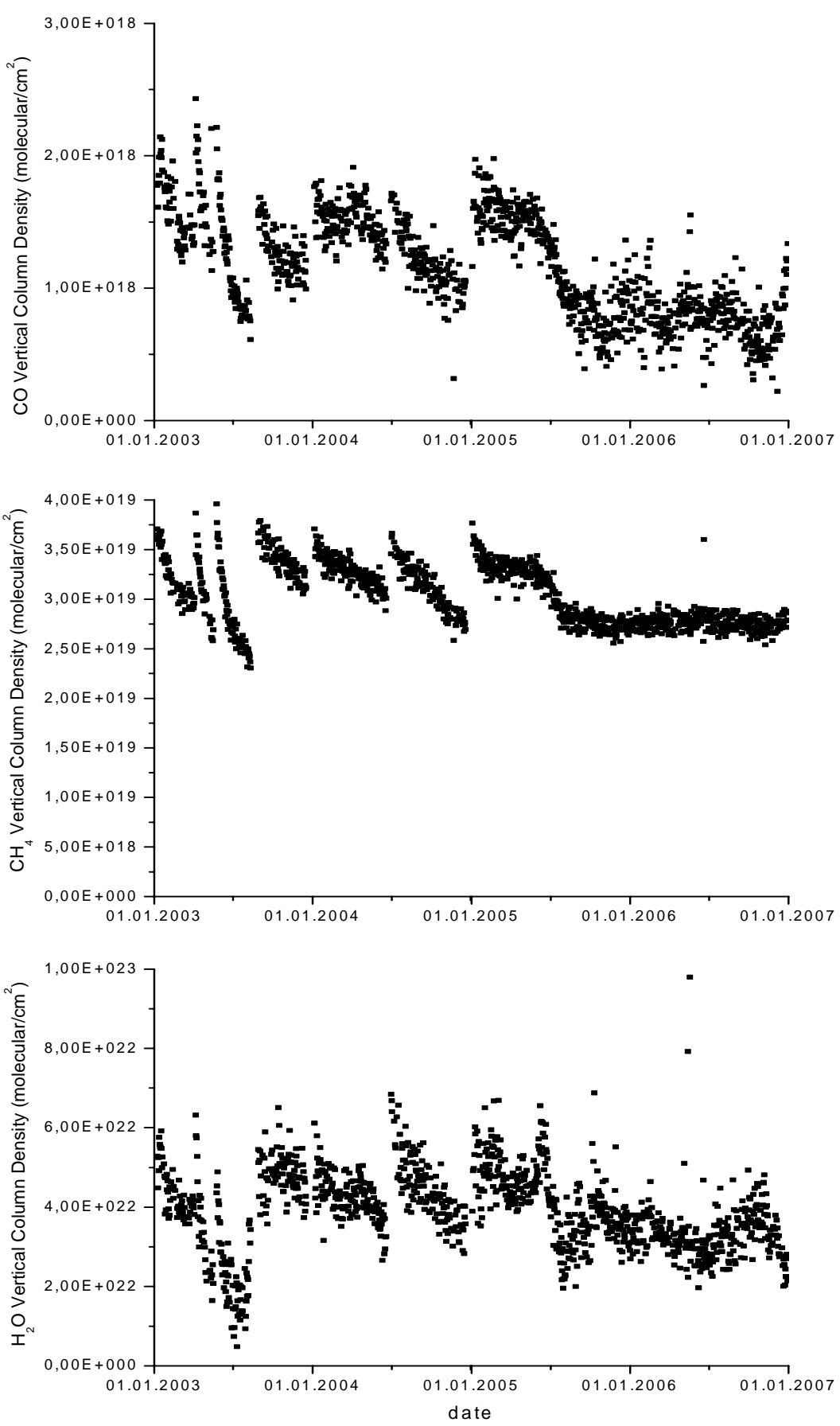

Fig. A1. Time series of the VCDs of $\mathrm{CO}$ (top), $\mathrm{CH}_{4}$ (middle) and $\mathrm{H}_{2} \mathrm{O}$ (bottom) averaged over Sahara $\left(20^{\circ} \mathrm{N}\right.$ to $28^{\circ} \mathrm{N}$; $8^{\circ} \mathrm{W}$ to $\left.28^{\circ} \mathrm{E}\right)$ for each day in the period 2003 to 2006. 

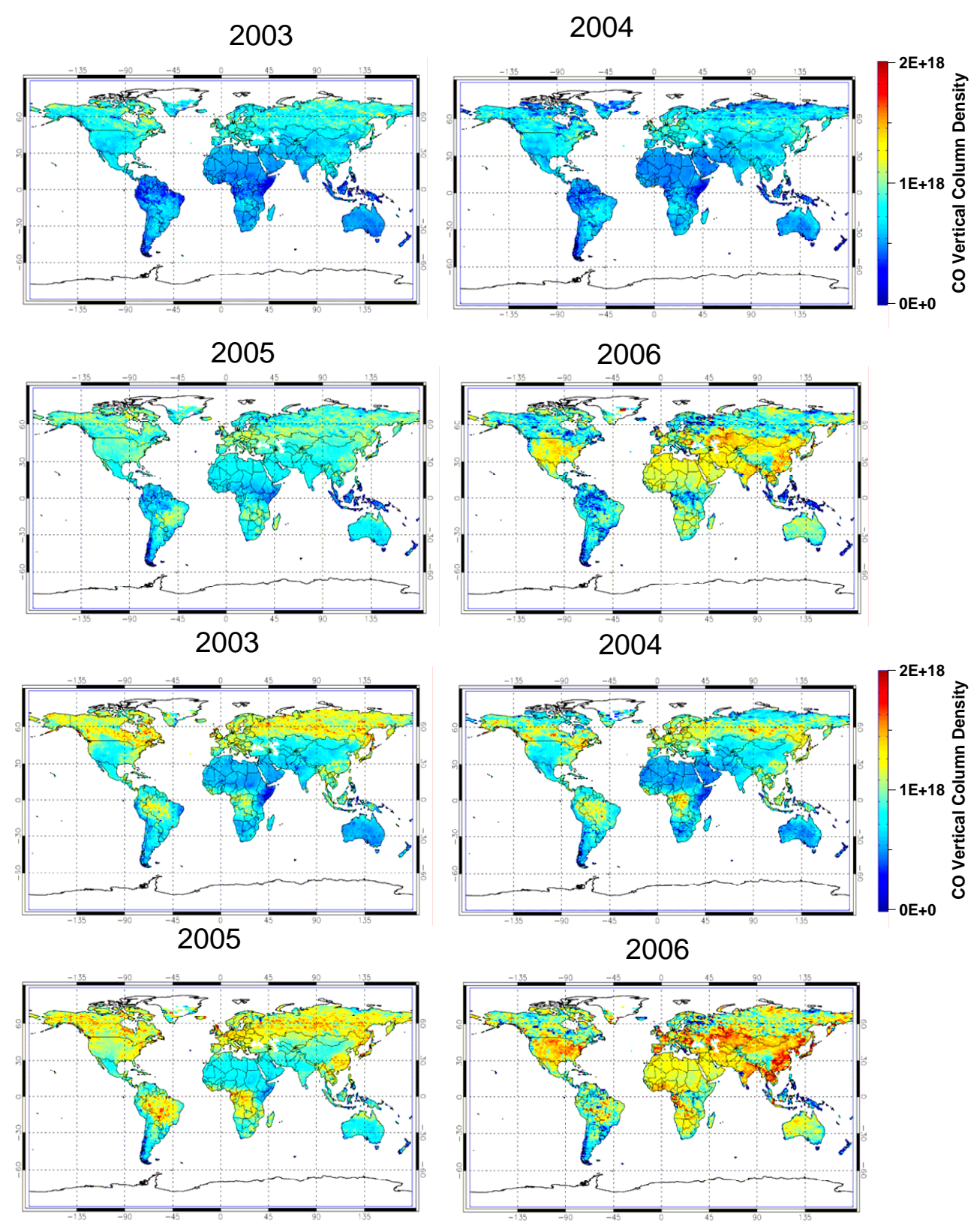

Fig. A2. Differences of the SCIAMACHY CO VCD for the different steps of our retrieval. Top: SCIA CO VCD with MOPITT normalisation minus MOPITT normalisation without MOPITT normalisation. Bottom: SCIA CO VCD with MOPITT normalisation and cloud correction minus MOPITT normalisation without MOPITT normalisation. 


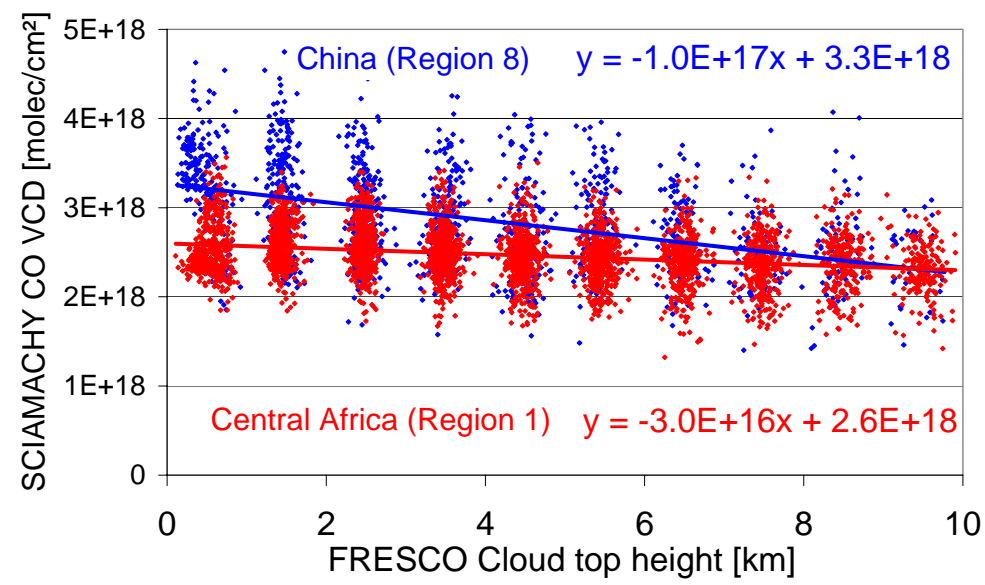

Fig. A3. Dependence of the CO VCD on the cloud top height (FRESCO) for effective cloud fractions $<20 \%$. Measurements for January to March 2004-2005.

without normalization without cloud correction

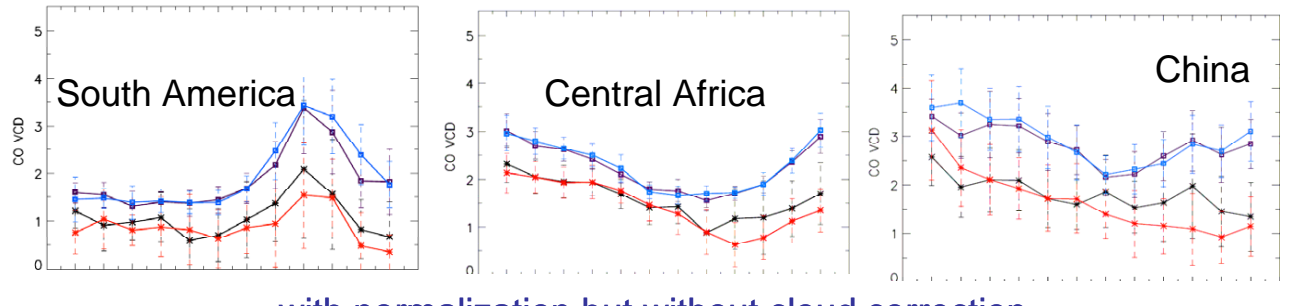

with normalization but without cloud correction

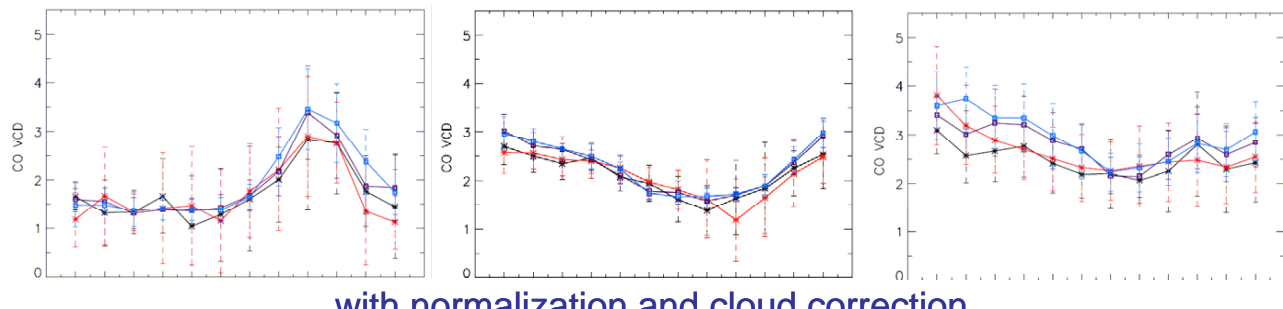

with normalization and cloud correction
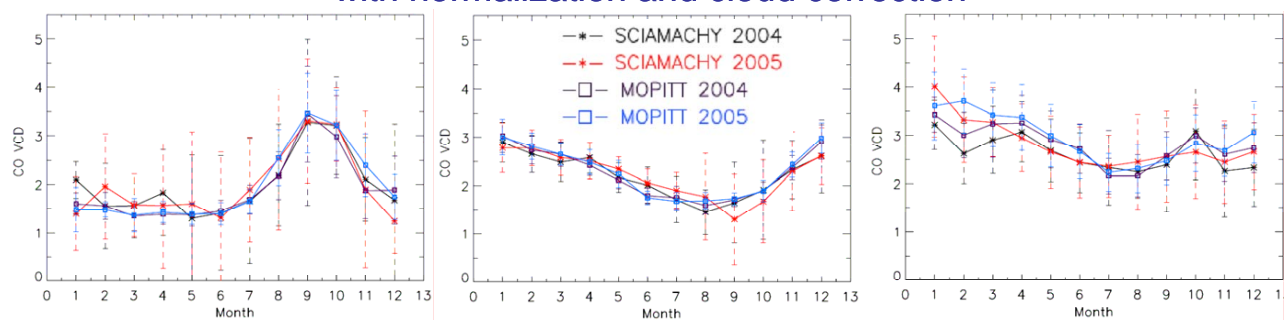

Fig. A4. Comparison of the monthly mean CO VCD (in units of $10^{18}$ molec $\mathrm{cm}^{-2}$ ) derived from coincident measurements of SCIAMACHY and MOPITT for selected regions. In the top panel uncorrected SCIAMACHY CO VCDs are shown, in the middle panel, SCIAMACHY CO VCD after normalisation are shown, and in the bottom panel SCIAMACHY CO VCDs after additional cloud correction are shown (the same data as in Fig. 11). 
Southeast Africa (region 2 in Fig. 8)
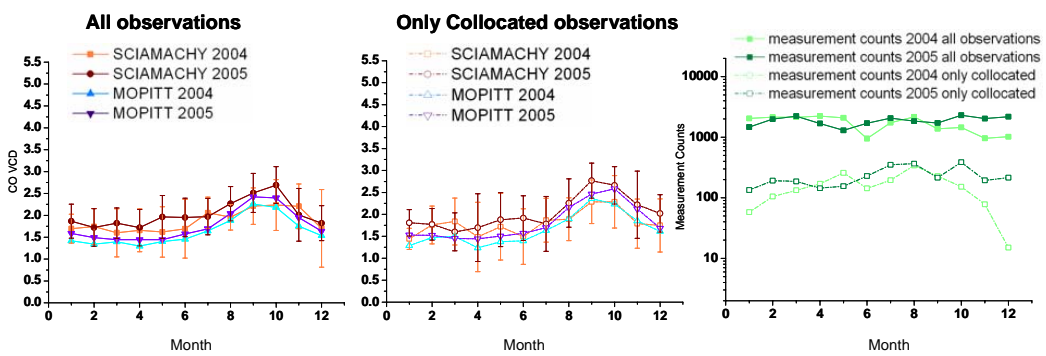

Southwest Africa (region 3 in Fig. 8)
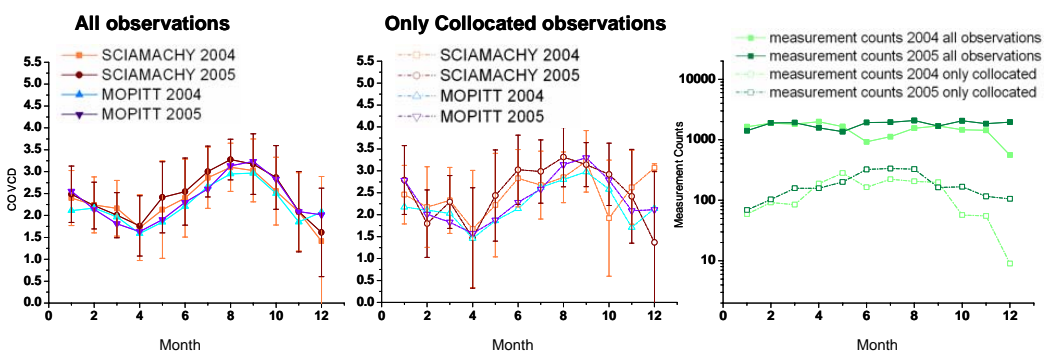

Northern Australia (region 5 in Fig. 8)
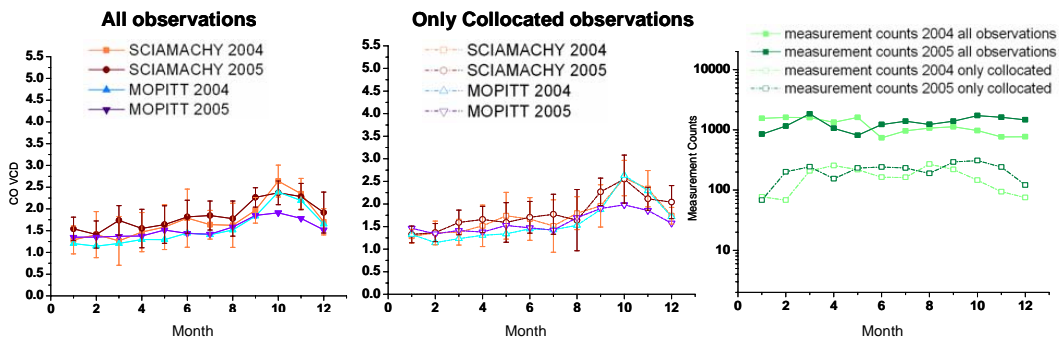

Southern Asia (region 6 in Fig. 8)
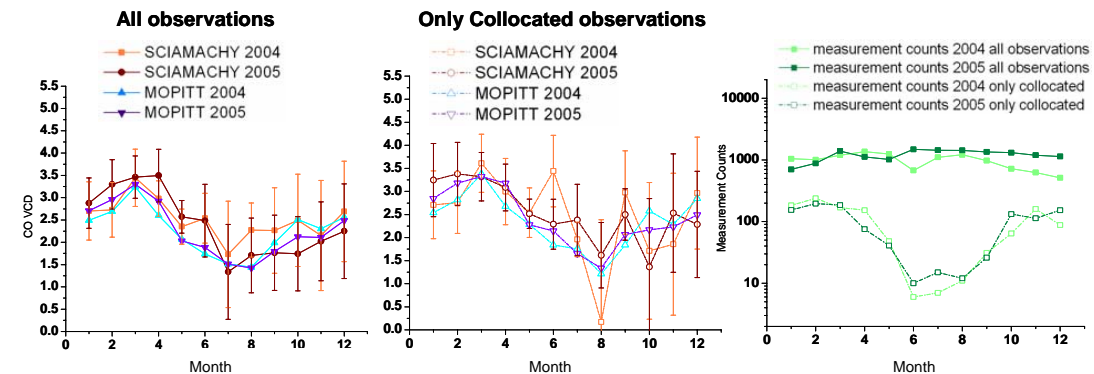

Indonesia (region 7 in Fig. 8)
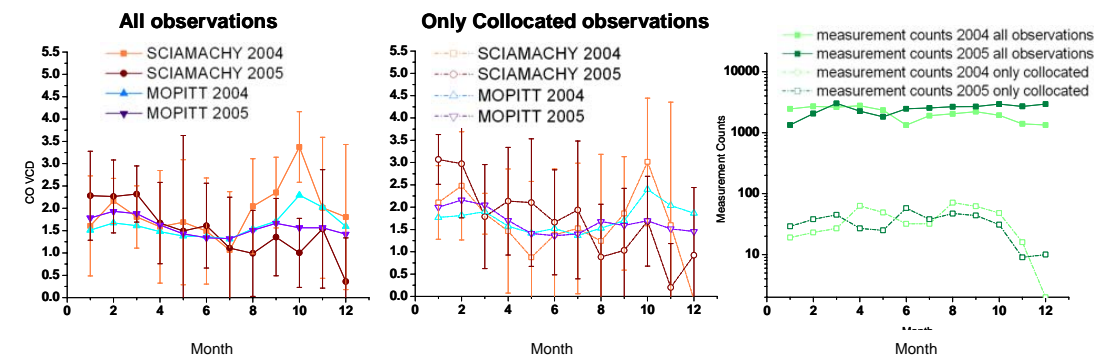

Fig. A5. Comparison of the monthly mean CO VCD (in units of $10^{18} \mathrm{molec}^{-2}$ ) derived from SCIAMACHY and MOPITT. In the left column of the figure all measurements within the selected regions (see Fig. 6) are considered. In the middle column only collocated and coincident observations are used. The error bar of SCIAMACHY refers to the unbiased estimator of a weighted population variance. In the right column the number of selected observations are indicated (please notice the logarithmic scale). 


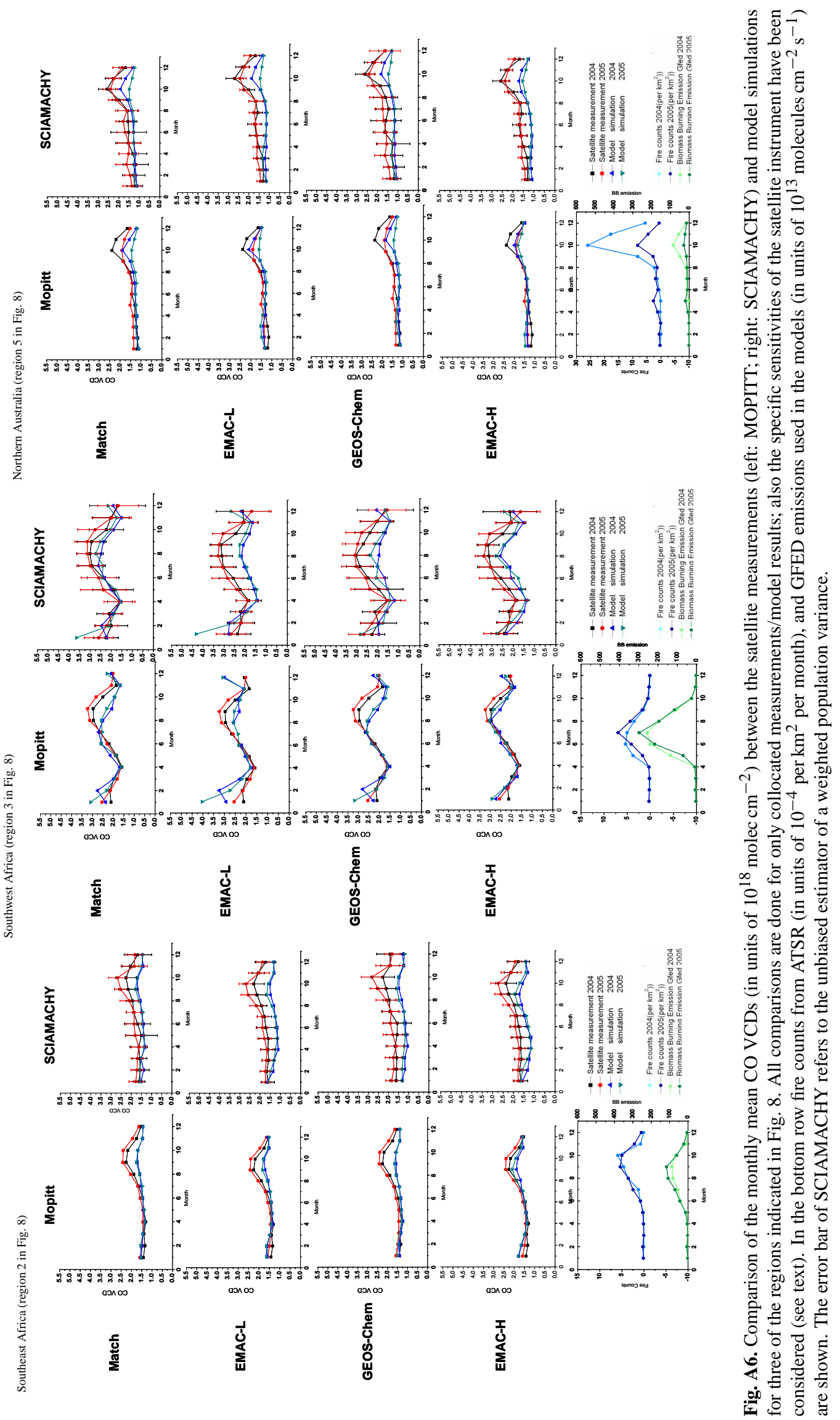




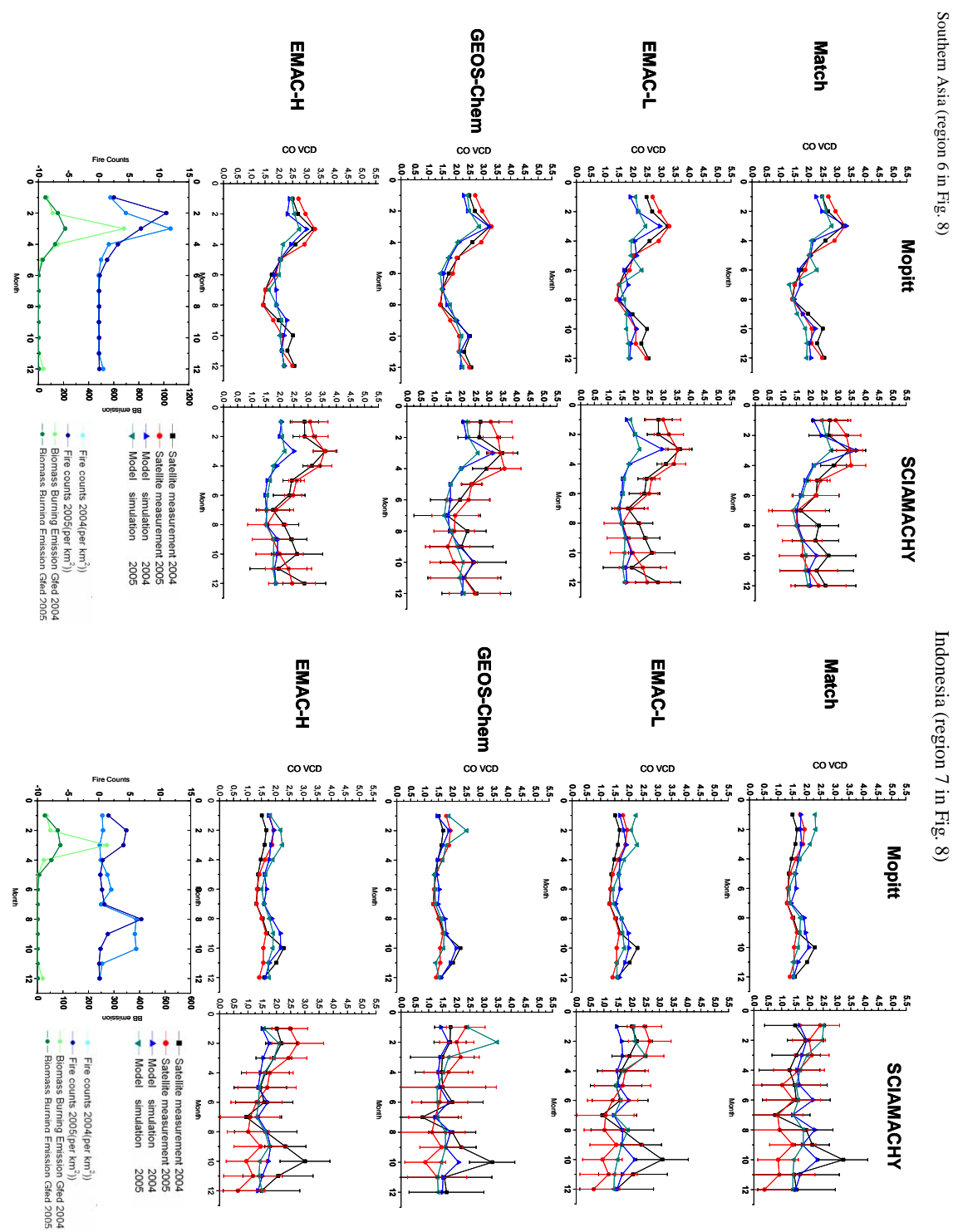


Acknowledgements. We used several external data sets in this study and we want to thank especially the following persons and institutions: ESA for providing SCIAMACHY Lv-1 satellite data. MOPITT CO data were obtained from the NASA Langley Research Center Atmospheric Science Data Center, http://eosweb.larc.nasa. gov/PRODOCS/mopitt/table_mopitt.html. FRESCO cloud data were obtained from Tropospheric Emission Monitoring Internet Service, http://www.temis.nl/fresco/.

MODIS albedo data were obtained from NASA's Earth Observing System (EOS), http://modis-atmos.gsfc.nasa.gov/ALBEDO/. ATSR fire counts were obtained from European Space Agency, http://shark1.esrin.esa.it/ionia/FIRE/. The GEOS-Chem simulation was carried out at the Atmospheric Physics and Composition Modelling Group led by Dylan B. Jones of the University of Toronto. J. L. is grateful to Prof. Jones for his generous help. The GEOS-Chem model is managed at Harvard University with support from the NASA Atmospheric Chemistry Modeling and Analysis Program. We want to thank A. Gloudemans for fruitful discussions. Peter Hoor was funded by the German French DFG/INSU-CNRS project POMODORO. Part of the research described in this publication was carried out at the Jet Propulsion Laboratory, California Institute of Technology, under a contract with the National Aeronautics and Space Administration. TCCON data were obtained from the TCCON Data Archive, operated by the California Institute of Technology from the website at http://tccon.ipac.caltech.edu/ (Wunsch et al., 2011). Additional FTIR data used in this publication were obtained as part of the Network for the Detection of Atmospheric Composition Change (NDACC) and are publicly available (see http://www.ndacc.org). We thank Jos de Laat for his very helpful and constructive comments and for his help in getting access to additional FTIR data.

The service charges for this open access publication have been covered by the Max Planck Society.

Edited by: P. O. Wennberg

\section{References}

Akagi, S. K., Yokelson, R. J., Wiedinmyer, C., Alvarado, M. J., Reid, J. S., Karl, T., Crounse, J. D., and Wennberg, P. O.: Emission factors for open and domestic biomass burning for use in atmospheric models, Atmos. Chem. Phys., 11, 4039-4072, doi:10.5194/acp-11-4039-2011, 2011.

Andreae, M. O. and Merlet, P.: Emission of trace gases and aerosols from biomass burning, Global Biogeochem. Cy., 15(1), 955-966, doi:10.1029/2000GB001382, 2001.

Bey, I., Jacob, D. J., Yantosca, R. M., Logan, J. A., Field, B. D., Fiore, A. M., Li, Q. B., Liu, H. G. Y., Mickley, L. J., and Schultz, M. G.: Global modeling of tropospheric chemistry with assimilated meteorology: Model description and evaluation, J. Geophys. Res.-Atmos., 106, 23073-23095, 2001.

Bovensmann, H., Burrows, J. P., Buchwitz, M., Frerick, J., Noel, S., Rozanov, V. V., Chance, K. V., and Goede, A. P. H.: SCIAMACHY: Mission objectives and measurement modes, J. Atmos. Sci., 56, 127-150, 1999.
Buchwitz, M., Rozanov, V. V., and Burrows, J. P.: A near-infrared optimized DOAS method for the fast global retrieval of atmospheric $\mathrm{CH}_{4}, \mathrm{CO}, \mathrm{Co}_{2}, \mathrm{H}_{2} \mathrm{O}$, and $\mathrm{N}_{2} \mathrm{O}$ total column amounts from SCIAMACHY Envisat-1 nadir radiances, J. Geophys. Res.Atmos., 105, 15231-15245, 2000.

Buchwitz, M., de Beek, R., Bramstedt, K., Noël, S., Bovensmann, H., and Burrows, J. P.: Global carbon monoxide as retrieved from SCIAMACHY by WFM-DOAS, Atmos. Chem. Phys., 4, 19451960, doi:10.5194/acp-4-1945-2004, 2004.

Buchwitz, M., de Beek, R., Noël, S., Burrows, J. P., Bovensmann, H., Bremer, H., Bergamaschi, P., Krner, S., and Heimann, M.: Carbon monoxide, methane and carbon dioxide columns retrieved from SCIAMACHY by WFM-DOAS: year 2003 initial data set, Atmos. Chem. Phys., 5, 3313-3329, doi:10.5194/acp-53313-2005, 2005.

Buchwitz, M., de Beek, R., Noel, S., Burrows, J. P., and Bovensmann, H.: Carbon monoxide, methane and carbon dioxide over China retrieved from SCIAMACHY/ENVISAT by WFMDOAS, Proceedings of the 2005 Dragon Symposium (ESA-SP-611), 159-165, 27 June-1 July 2005, Santorini, Greece, 2006b.

Buchwitz, M., de Beek, R., Noel, S., Burrows, J. P., and Bovensmann, H.: Carbon monoxide, methane and carbon dioxide over China retrieved from SCIAMACHY/ENVISAT by WFMDOAS, Esa Sp. Publ., 611, 159-165, 429, 2006b.

Buchwitz, M., Khlystova, I., Bovensmann, H., and Burrows, J. P.: Three years of global carbon monoxide from SCIAMACHY: comparison with MOPITT and first results related to the detection of enhanced CO over cities, Atmos. Chem. Phys., 7, 23992411, doi:10.5194/acp-7-2399-2007, 2007.

Burrows, J. P., Hoelzle, E., Goede, A. P. H., Visser, H., and Fricke, W.: Sciamachy - Scanning Imaging Absorption Spectrometer for Atmospheric Chartography, Acta Astronaut., 35, 445-451, 1995.

Cicerone, R. J.: How has the Atmospheric Concentration of CO changed, in: The Changing Atmosphere, edited by: Rowland, F. S., Isaksen, I. S. A., Wiley, Chicester, UK, 1988.

Crutzen, P. J. and Gidel, L. T.: A two-dimensional photochemical model of the atmosphere. 2: The tropospheric budgets of anthropogenic chlorocarbons $\mathrm{CO}, \mathrm{CH}_{4}, \mathrm{CH}_{3} \mathrm{Cl}$ and the effect of various. $\mathrm{NO}_{\mathrm{x}}$ sources on tropospheric ozone, J. Geophys. Res., 88, 6641-6661, 1983.

de Laat, A. T. J., Gloudemans, A. M. S., Schrijver, H., van den Broek, M. M. P., Meirink, J. F., Aben, I., and Krol, M.: Quantitative analysis of SCIAMACHY carbon monoxide total column measurements, Geophys. Res. Lett., 33, L07807, doi:10.1029/2005g1025530, 2006.

de Laat, A. T. J., Gloudemans, A. M. S., Aben, I., Krol, M., Meirink, J. F., van der Werf, G. R., and Schrijver, H.: Scanning Imaging Absorption Spectrometer for Atmospheric Chartography carbon monoxide total columns: Statistical evaluation and comparison with chemistry transport model results, J. Geophys. Res.-Atmos., 112, D21306, doi:10.1029/2007jd009378, 2007.

de Laat, A. T. J., Gloudemans, A. M. S., Aben, I., and Schrijver, H.: Global evaluation of SCIAMACHY and MOPITT carbon monoxide column differences for 2004-2005, J. Geophys. Res.Atmos., 115, D06307, doi:10.1029/2009jd012698, 2010.

Deeter, M. N., Emmons, L. K., Francis, G. L., Edwards, D. P., Gille, J. C., Warner, J. X., Khattatov, B., Ziskin, D., Lamarque, J. F., Ho, S. P., Yudin, V., Attie, J. L., Packman, D., Chen, J., Mao, D., and Drummond, J. R.: Operational carbon monoxide retrieval 
algorithm and selected results for the MOPITT instrument, J. Geophys. Res.-Atmos., 108, 4399, doi:10.1029/2002jd003186, 2003.

Deeter, M. N., Edwards, D. P., Gille, J. C., Emmons, L. K., Francis, G., Ho, S.-P., Mao, D., Masters, D., Worden, H., Drummond, J. R., and Novelli, P. C.: The MOPITT version 4 CO product: Algorithm enhancements, validation, and long-term stability, J. Geophys. Res., 115, D07306, doi:10.1029/2009JD013005, 2010.

Dils, B., De Maziere, M., Blumenstock, T., Hase, F., Kramer, I., Mahieu, E., Demoulin, P., Duchatelet, P., Mellqvist, J., Strandberg, A., Buchwitz, M., Khlystova, I., Schneising, O., Velazco, V., Notholt, J., Sussmann, R., and Stremme, W.: Validation of WFMDOAS v0.6 $\mathrm{CO}$ and v1.0 $\mathrm{CH}_{4}$ scientific products using European ground-based FTIR measurements, proceedings of the Third Workshop on the Atmospheric Chemistry Validation of ENVISAT (ACVE-3), 4-7 Dec. 2006, ESA/ESRIN, Frascati, Italy, ESA Publications Division Special Publication SP642 (CD), 2006a.

Dils, B., De Mazire, M., Mller, J. F., Blumenstock, T., Buchwitz, M., de Beek, R., Demoulin, P., Duchatelet, P., Fast, H., Frankenberg, C., Gloudemans, A., Griffith, D., Jones, N., Kerzenmacher, T., Kramer, I., Mahieu, E., Mellqvist, J., Mittermeier, R. L., Notholt, J., Rinsland, C. P., Schrijver, H., Smale, D., Strandberg, A., Straume, A. G., Stremme, W., Strong, K., Sussmann, R., Taylor, J., van den Broek, M., Velazco, V., Wagner, T., Warneke, T., Wiacek, A., and Wood, S.: Comparisons between SCIAMACHY and ground-based FTIR data for total columns of $\mathrm{CO}, \mathrm{CH}_{4}, \mathrm{CO}_{2}$, and $\mathrm{N}_{2} \mathrm{O}$, Atmos. Chem. Phys., 6, 1953-1976, doi:10.5194/acp6-1953-2006, 2006b.

Drummond, J. R. and Mand, G. S.: The measurements of pollution in the troposphere (MOPITT) instrument: Overall performance and calibration requirements, J. Atmos. Ocean Tech., 13, 314320, 1996

Emmons, L. K., Deeter, M. N., Gille, J. C., Edwards, D. P., Attie,J.L., Warner, J., Ziskin,D., Francis, G., Khattatov, B., Yudin,V., Lamarque, J.-F., Ho,S.-P., Mao, D., Chen, J. S., Drummond, J., Novelli, P., Sachse, G., Coffey, M. T., Hannigan, J. W. , Gerbig,C. , Kawakami, S., Kondo, Y. , Takegawa, N. , Schlager, H., Baehr, J., and Ziereis, H.: Validation of Measurements of Pollution in the Troposphere (MOPITT) CO retrievals with aircraft in situ profiles, J. Geophys. Res., 109(D3), D03309, doi:10.1029/2003JD004101, 14 February 2004, 2004.

Emmons, L. K., Edwards, D. P., Deeter, M. N., Gille, J. C., Campos, T., Nédélec, P., Novelli, P., and Sachse, G.: Measurements of Pollution In The Troposphere (MOPITT) validation through 2006, Atmos. Chem. Phys., 9, 1795-1803, doi:10.5194/acp-91795-2009, 2009.

Eskes, H. J. and Boersma, K. F.: Averaging kernels for DOAS totalcolumn satellite retrievals, Atmos. Chem. Phys., 3, 1285-1291, doi:10.5194/acp-3-1285-2003, 2003.

Frankenberg, C., Platt, U., and Wagner, T.: Iterative maximum a posteriori (IMAP)-DOAS for retrieval of strongly absorbing trace gases: Model studies for $\mathrm{CH}_{4}$ and $\mathrm{CO}_{2}$ retrieval from near infrared spectra of SCIAMACHY onboard ENVISAT, Atmos. Chem. Phys., 5, 9-22, doi:10.5194/acp-5-9-2005, 2005.

Frankenberg, C., Platt, U., and Wagner, T.: Retrieval of CO from SCIAMACHY onboard ENVISAT: detection of strongly polluted areas and seasonal patterns in global $\mathrm{CO}$ abundances, Atmos. Chem. Phys., 5, 1639-1644, doi:10.5194/acp-5-1639-2005,
2005.

Galanter, M., Levy, H., and Carmichael, G. R.: Impacts of biomass burning on tropospheric $\mathrm{CO}, \mathrm{NO}_{\mathrm{x}}$, and O-3, J. Geophys. Res.Atmos., 105, 6633-6653, 2000.

George, M., Clerbaux, C., Hurtmans, D., Turquety, S., Coheur, P.F., Pommier, M., Hadji-Lazaro, J., Edwards, D. P., Worden, H., Luo, M., Rinsland, C., and McMillan, W.: Carbon monoxide distributions from the IASI/METOP mission: evaluation with other space-borne remote sensors, Atmos. Chem. Phys., 9, 8317-8330, doi:10.5194/acp-9-8317-2009, 2009.

Gloudemans, A., Schrijver, H., Straume, A., Aben, I., Maurellis, A., Buchwitz, M., de Beek, R., Frankenberg, C., and Wagner, T.: $\mathrm{CH}_{4}$ and $\mathrm{CO}$ total columns from SCIAMACHY: comparisons with TM3 and MOPITT, in: Remote Sensing of Clouds and the Atmosphere VIII, of Proceedings ACVE2, 5235, 3-7 May, Frascati, Italy, 2004.

Gloudemans, A. M. S., Schrijver, H., Kleipool, Q., van den Broek, M. M. P., Straume, A. G., Lichtenberg, G., van Hees, R. M., Aben, I., and Meirink, J. F.: The impact of SCIAMACHY nearinfrared instrument calibration on $\mathrm{CH} 4$ and $\mathrm{CO}$ total columns, Atmos. Chem. Phys., 5, 2369-2383, doi:10.5194/acp-5-23692005, 2005.

Gloudemans, A. M. S., Krol, M. C., Meirink, J. F., de Laat, A. T. J., van der Werf, G. R., Schrijver, H., van den Broek, M. M. P., and Aben, I.: Evidence for long-range transport of carbon monoxide in the Southern Hemisphere from SCIAMACHY observations, Geophys. Res. Lett., 33, L16807, doi:10.1029/2006g1026804, 2006.

Gloudemans, A. M. S., Schrijver, H., Hasekamp, O. P., and Aben, I.: Error analysis for $\mathrm{CO}$ and $\mathrm{CH} 4$ total column retrievals from SCIAMACHY 2.3um spectra, Atmos. Chem. Phys., 8, 39994017, doi:10.5194/acp-8-3999-2008, 2008.

Gloudemans, A. M. S., de Laat, A. T. J., Schrijver, H., Aben, I., Meirink, J. F., and van der Werf, G. R.: SCIAMACHY CO over land and oceans: 2003-2007 interannual variability, Atmos. Chem. Phys., 9, 3799-3813, doi:10.5194/acp-9-3799-2009, 2009.

Granier, C., Petron, G., Müller, J. F., and Brasseur, G.: The impact of natural and anthropogenic hydrocarbons on the tropospheric budget of carbon monoxide, Atmos. Environ., 34, 5255-5270, 2000 .

Guenther, A., Karl, T., Harley, P., Wiedinmyer, C., Palmer, P. I., and Geron, C.: Estimates of global terrestrial isoprene emissions using MEGAN (Model of Emissions of Gases and Aerosols from Nature), Atmos. Chem. Phys., 6, 3181-3210, doi:10.5194/acp-63181-2006, 2006.

Hack, J. J.: Parameterization of moist convection in the National Center for Atmospheric Research Community Climate Model (CCM2), J. Geophys. Res., 99, 5551-5568, 1994.

Holloway, T., Levy, H., and Kasibhatla, P.: Global distribution of carbon monoxide, J. Geophys. Res.-Atmos., 105, 12123-12147, 2000.

Jöckel, P., Sander, R., Kerkweg, A., Tost, H., and Lelieveld, J.: Technical Note: The Modular Earth Submodel System (MESSy) - a new approach towards Earth System Modeling, Atmos. Chem. Phys., 5, 433-444, doi:10.5194/acp-5-433-2005, 2005.

Jöckel, P., Tost, H., Pozzer, A., Brhl, C., Buchholz, J., Ganzeveld, L., Hoor, P., Kerkweg, A., Lawrence, M. G., Sander, R., Steil, B., Stiller, G., Tanarhte, M., Taraborrelli, D., van Aardenne, J., 
and Lelieveld, J.: The atmospheric chemistry general circulation model ECHAM5/MESSy1: consistent simulation of ozone from the surface to the mesosphere, Atmos. Chem. Phys., 6, 50675104, doi:10.5194/acp-6-5067-2006, 2006.

Jöckel, P., Kerkweg, A., Pozzer, A., Sander, R., Tost, H., Riede, H., Baumgaertner, A., Gromov, S., and Kern, B.: Development cycle 2 of the Modular Earth Submodel System (MESSy2), Geosci. Model Dev., 3, 717-752, doi:10.5194/gmd-3-717-2010, 2010.

Justice, C. O., Vermote, E., Townshend, J. R. G., Defries, R., Roy, D. P., Hall, D. K., Salomonson, V. V., Privette, J. L., Riggs, G., Strahler, A., Lucht, W., Myneni, R. B., Knyazikhin, Y., Running, S. W., Nemani, R. R., Wan, Z. M., Huete, A. R., van Leeuwen, W., Wolfe, R. E., Giglio, L., Muller, J. P., Lewis, P., and Barnsley, M. J.: The Moderate Resolution Imaging Spectroradiometer (MODIS): Land remote sensing for global change research, Ieee T. Geosci. Remote, 36, 1228-1249, 1998.

Kalnay, E., Kanamitsu, M., and Baker, W. E.: Global Numerical Weather Prediction at the National-Meteorological-Center, B. Am. Meteorol. Soc., 71, 1410-1428, 1990.

Kerkweg, A., Sander, R., Tost, H., and Jöckel, P.: Technical note: Implementation of prescribed (OFFLEM), calculated (ONLEM), and pseudo-emissions (TNUDGE) of chemical species in the Modular Earth Submodel System (MESSy), Atmos. Chem. Phys., 6, 3603-3609, doi:10.5194/acp-6-3603-2006, 2006.

Kerkweg, A., Buchholz, J., Ganzeveld, L., Pozzer, A., Tost, H., and Jöckel, P.: Technical Note: An implementation of the dry removal processes DRY DEPosition and SEDImentation in the Modular Earth Submodel System (MESSy), Atmos. Chem. Phys., 6, 4617-4632, doi:10.5194/acp-6-4617-2006, 2006.

Koelemeijer, R. B. A., Stammes, P., Hovenier, J. W., and de Haan, J. F.: A fast method for retrieval of cloud parameters using oxygen A band measurements from the Global Ozone Monitoring Experiment, J. Geophys. Res., 106, 3475-3490, 2001.

Kopacz, M., Jacob, D. J., Fisher, J. A., Logan, J. A., Zhang, L., Megretskaia, I. A., Yantosca, R. M., Singh, K., Henze, D. K., Burrows, J. P., Buchwitz, M., Khlystova, I., McMillan, W. W., Gille, J. C., Edwards, D. P., Eldering, A., Thouret, V., and Nedelec, P.: Global estimates of $\mathrm{CO}$ sources with high resolution by adjoint inversion of multiple satellite datasets (MOPITT, AIRS, SCIAMACHY, TES), Atmos. Chem. Phys., 10, 855-876, doi:10.5194/acp-10-855-2010, 2010.

Krijger, J. M., van Weele, M., Aben, I., and Frey, R.: Technical Note: The effect of sensor resolution on the number of cloud-free observations from space, Atmos. Chem. Phys., 7, 2881-2891, doi:10.5194/acp-7-2881-2007, 2007.

Lawrence, M. G., Crutzen, P. J., Rasch, P. J., Eaton, B. E., and Mahowald, N. M.: A model for studies of tropospheric photochemistry: Description, global distributions, and evaluation, J. Geophys. Res.-Atmos., 104, 26245-26277, 1999.

Lawrence, M. G., Rasch, P. J., von Kuhlmann, R., Williams, J., Fischer, H., de Reus, M., Lelieveld, J., Crutzen, P. J., Schultz, M., Stier, P., Huntrieser, H., Heland, J., Stohl, A., Forster, C., Elbern, H., Jakobs, H., and Dickerson, R. R.: Global chemical weather forecasts for field campaign planning: predictions and observations of large-scale features during MINOS, CONTRACE, and INDOEX, Atmos. Chem. Phys., 3, 267-289, doi:10.5194/acp-3267-2003, 2003.

Lelieveld, J., Crutzen, P. J., Andreae, M. O., Brenninkmeijer, C. A. M., Campos, T., Cass, G. R., Dickerson, G. R., Fischer, H., de Gouw, J. A., Hansel, A., Jefferson, A., Kley, D., de Laat, A. T. J., Lal, S., Lawrence, M. G., Lobert, J. M., Mayol-Bracero, O., Mitra, A. P., Novakov, T., Oltmans, S. J., Prather, K. A., Ramanathan, V., Reiner, T., Rodhe, H., Scheeren, H. A., Sikka, D., and Williams, J.: The Indian Ocean Experiment: Widespread air pollution from South and South-East Asia, Science, 291, 10311036, 2001.

Leitão, J., Richter, A., Vrekoussis, M., Kokhanovsky, A., Zhang, Q. J., Beekmann, M., and Burrows, J. P.: On the improvement of $\mathrm{NO}_{2}$ satellite retrievals - aerosol impact on the airmass factors, Atmos. Meas. Tech., 3, 475-493, doi:10.5194/amt-3-475-2010, 2010.

Liu, C.: Evaluating the $\mathrm{CO}$ distributions from current atmospheric chemistry models using satellite observations from MOPITT and SCIAMACHY, PhD-thesis, University of Heidelberg, Germany, 2010.

Liu, J., Drummond, J. R., Li, Q., Gille, J. C., Ziskin, D.C.: Satellite mapping of $\mathrm{CO}$ emission from forest fires in Northwest America using MOPITT measurements, Remote Sens. Environ., 95, 502516, 2005.

Logan, J. A., Prather, M. J., Wofsy, S. C., and Mcelroy, M. B.: Tropospheric Chemistry - a Global Perspective, J. Geophys. Res.Oc. Atm., 86, 7210-7254, 1981.

Nakajima, T. and King, M. D.: Determination of the OpticalThickness and Effective Particle Radius of Clouds from Reflected Solar-Radiation Measurements 1. Theory, J. Atmos. Sci., 47, 1878-1893, 1990.

Nordeng, T. E.: Extended versions of the convective parametrization scheme at ECMWF and their impact on the mean and transient activity of the model in the tropics, Tech. rep., ECWMF, 1994.

Olivier, J. G. J. and Berdowski, J. J. M.: Global emissions sources and sinks. In: The Climate System, edited by: Berdowski, J., Guicherit, R., and Heij, B. J., 33-78, A. A. Balkema Publishers/Swets and Zeitlinger Publishers, Lisse, The Netherlands, 2001.

Platt, U. and Stutz, J.: Differential Optical Absorption Spectroscopy, in: Principles and Applications, Springer, Berlin, Heidelberg, Germany, ISBN 978-3540211938 http://books.google. com/books, 2008.

Pozzer, A., Jöckel, P., Tost, H., Sander, R., Ganzeveld, L., Kerkweg, A., and Lelieveld, J.: Simulating organic species with the global atmospheric chemistry general circulation model ECHAM5/MESSy1: a comparison of model results with observations, Atmos. Chem. Phys., 7, 2527-2550, doi:10.5194/acp-72527-2007, 2007.

Rasch, P. J., Mahowald, N. M., and Eaton, B. E.: Representations of transport, convection, and the hydrologic cycle in chemical transport models: Implications for the modeling of short-lived and soluble species, J. Geophys. Res.-Atmos., 102, 28127-28138, 1997.

Rodgers, C. D.: Retrieval of Atmospheric-Temperature and Composition from Remote Measurements of Thermal-Radiation, Rev. Geophys., 14, 609-624, 1976.

Roeckner, E., R. Brokopf, M. Esch, M. Giorgetta, S. Hagemann, L. Kornblueh, E. Manzini, R. Schlese, U. Schulzweida, Sensitivity of simulated climate to horizontal and vertical resolution in the ECHAM5 atmosphere model, J. Climate, 19, 3771-3791, 2006.

Sander, R., Kerkweg, A., Jöckel, P., and Lelieveld, J.: Technical 
note: The new comprehensive atmospheric chemistry module MECCA, Atmos. Chem. Phys., 5, 445-450, doi:10.5194/acp-5445-2005, 1425, 1451, 1452, 2005.

Schrijver, H.: Retrieval of carbon monoxide, methane and nitrous oxide from SCIAMACHY measurements, in: ESA WPP-161 1, vol. 5235, Proc. ESAMS, European Symposium on Atmospheric Measurements from Space, 285-294, Estec, Nordwijk, The Netherlands, 2004.

Shindell, D. T., Faluvegi, G., Stevenson, D. S., Krol, M. C., Emmons, L. K., Lamarque, J. F., Petron, G., Dentener, F. J., Ellingsen, K., Schultz, M. G., Wild, O., Amann, M., Atherton, C. S., Bergmann, D. J., Bey, I., Butler, T., Cofala, J., Collins, W. J., Derwent, R. G., Doherty, R. M., Drevet, J., Eskes, H. J., Fiore, A. M., Gauss, M., Hauglustaine, D. A., Horowitz, L. W., Isaksen, I. S. A., Lawrence, M. G., Montanaro, V., Muller, J. F., Pitari, G., Prather, M. J., Pyle, J. A., Rast, S., Rodriguez, J. M., Sanderson, M. G., Savage, N. H., Strahan, S. E., Sudo, K., Szopa, S., Unger, N., van Noije, T. P. C., and Zeng, G.: Multimodel simulations of carbon monoxide: Comparison with observations and projected near-future changes, J. Geophys. Res.Atmos., 111, D19306, doi:10.1029/2006jd007100, 2006.

Solomon, S., Schmeltekopf, A. L., and Sanders, R. W.: On the interpretation of zenith sky absorption measurements, J. Geophys. Res, 92, 8311-8319, 1987.

Straume, A. G., Schrijver, H., Gloudemans, A. M. S., Houweling, S., Aben, I., Maurellis, A. N., de Laat, A. T. J., Kleipool, Q., Lichtenberg, G., van Hees, R., Meirink, J. F., and Krol, M.: The global variation of $\mathrm{CH}_{4}$ and $\mathrm{CO}$ as seen by SCIAMACHY, Adv. Space Res., 36, 821-827, doi:10.1016/j.asr.2005.03.027, 2005.

Tangborn, A., Stajner, I., Buchwitz, M., Khlystova, I., Pawson, S., Burrows, J., Hudman, R., and Nedelec, P.: Assimilation of SCIAMACHY total column CO observations: Global and regional analysis of data impact, J. Geophys. Res., 114, D07307, doi:10.1029/2008JD010781, 2009.

Tiedtke, M.: A comprehensive mass flux scheme for cumulus parametrization in large-scale models, Mon. Wea. Rev., 117, 1779-1800, 1989.
Tost, H., Jöckel, P., Kerkweg, A., Sander, R., and Lelieveld, J.: Technical note: A new comprehensive SCAVenging submodel for global atmospheric chemistry modelling, Atmos. Chem. Phys., 6, 565-574, doi:10.5194/acp-6-565-2006, 2006.

Turquety, S., Clerbaux, C., Law, K., Coheur, P.-F., Cozic, A., Szopa, S., Hauglustaine, D. A., Hadji-Lazaro, J., Gloudemans, A. M. S., Schrijver, H., Boone, C. D., Bernath, P. F., and Edwards, D. P.: CO emission and export from Asia: an analysis combining complementary satellite measurements (MOPITT, SCIAMACHY and ACE-FTS) with global modeling, Atmos. Chem. Phys., 8, 5187-5204, doi:10.5194/acp-8-5187-2008, 2008.

van der Werf, G. R., Randerson, J. T., Giglio, L., Collatz, G. J., Kasibhatla, P. S., and Arellano Jr., A. F.: Interannual variability in global biomass burning emissions from 1997 to 2004, Atmos. Chem. Phys., 6, 3423-3441, doi:10.5194/acp-6-3423-2006, 2006.

von Kuhlmann, R., Lawrence, M. G., Crutzen, P. J., and Rasch, P. J.: A model for studies of tropospheric ozone and nonmethane hydrocarbons: Model description and ozone results, J. Geophys. Res.-Atmos., 108, 4294, doi:10.1029/2002jd002893, 2003.

Wang, P., Stammes, P., van der A, R., Pinardi, G., and van Roozendael, M.: FRESCO+: an improved $\mathrm{O}_{2}$ A-band cloud retrieval algorithm for tropospheric trace gas retrievals, Atmos. Chem. Phys. Discuss., 8, 9697-9729, doi:10.5194/acpd-8-9697-2008, 2008.

Wunch, D., Toon, G. C., Blavier, J.-F. L., Washenfelder, R. A., Notholt, J., Connor, B. J., Griffith, D. W. T., Sherlock, V., Wennberg, P.O.: The Total Carbon Column Observing Network, Phil. Trans. R. Soc. A, 369, doi:10.1098/rsta.2010.0240, 2011.

Yevich, R. and Logan, J. A.: An assessment of biofuel use and burning of agricultural waste in the developing world, Global Biogeochem. Cy., 17(1), 1095, doi:10.1029/2002GB001952, 2003.

Zhang, G. J. and McFarlane, N. A.: Sensitivity of climate simulations to the parameterization of cumulus convection in the Canadian climate centre general circulation model, Atmos.-Ocean, 33, 407-446, 1995. 